\title{
Repair of composite-to-masonry bond using flexible matrix
}

\author{
Arkadiusz Kwiecień ${ }^{1}$, Gianmarco de Felice ${ }^{2 *}$, Daniel V. Oliveira ${ }^{3}$, Bogusław Zając ${ }^{1}$, Alessandro \\ Bellini $^{4}$, Stefano De Santis ${ }^{2}$, Bahman Ghiassi ${ }^{3}$, Gian Piero Lignola ${ }^{5}$, Paulo B. Lourenço ${ }^{3}$, Claudio \\ Mazzotti $^{6}$, Andrea Prota ${ }^{5}$
}

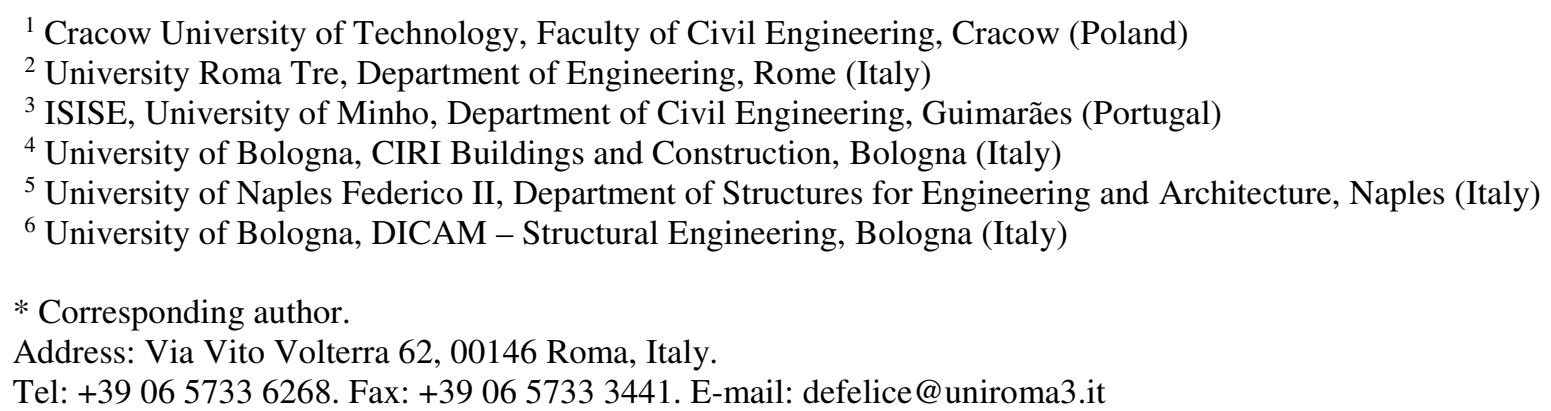

\begin{abstract}
The paper presents an experimental investigation on an innovative repair method, in which composite reinforcements, after debonding, are re-bonded to the substrate using a highly deformable polymer. In order to assess the effectiveness of this solution, shear bond tests were carried out on brick and masonry substrates within two Round Robin Test series organized within the RILEM TC 250-CSM: Composites for Sustainable strengthening of Masonry. Five laboratories from Italy, Poland and Portugal were involved. The shear bond performance of the reinforcement systems before and after repair were compared in terms of ultimate loads, load-displacement curves and strain distributions. The results showed that the proposed repair method may provide higher strength and ductility than stiff epoxy resins, making it an effective and cost efficient technique for several perspective structural applications.
\end{abstract}

\section{Keywords}

Masonry, repair, shear bond test, polymer PS, FRP, SRP

\section{INTRODUCTION}

Externally bonded composites are today widely adopted for the strengthening and repair of both reinforced concrete and masonry structures, in the form of either Fibre Reinforced Polymer (FRP) or Steel Reinforced Polymer (SRP). In the last decades, such strengthening solutions have been tested and applied to various masonry structural members, including walls (Valluzzi et al., 2002; Kubica et al., 2008), arches and vaults 
(Valluzzi et al., 2001; Jasienko et al., 2009; Oliveira et al., 2010; Giamundo et al., 2015), and columns (Micelli et al., 2004; Corradi et al., 2007), and on both modern and historical constructions (Flaga and Kwiecień, 2010; Valluzzi et al., 2014; de Felice et al., 2015b). Different textiles have been used, including glass, carbon, basalt, aramid and steel, whose effectiveness has been clearly shown by laboratory testing (see, amongst others, Celestini and Casadei, 2009; de Felice et al., 2015b; De Santis et al., 2015), field applications (Valluzzi et al., 2014) and numerical analyses (Lignola et al., 2009; Parisi et al., 2011; Lignola et al., 2012).

Composite reinforcements are generally bonded to masonry substrates using stiff epoxy resins or cement mortars, which in some cases (especially for applications to weak and brittle substrates) may not ensure proper ductility and compatibility properties (Modena, 2004; Valluzzi et al., 2014). More compatible bonding solutions have been tested recently making use of lime based mortar matrices (Ceroni et al., 2014; Ascione et al., 2015; De Santis et al., 2015). After one or two decades of service life, externally bonded reinforcements detach due to cyclic loading, long-term deterioration, and occurrence of severe events (e.g., earthquakes). Therefore, there is today the need of restoring the effectiveness of the damaged strengthening systems, possibly not by substitution but by repair and re-bonding, which may ensure lower cost and time of execution and is more sustainable in terms of environmental impact. A typical failure mode of FRP strips or laminates is the detachment from the substrate with the removal of a thin layer of material (Valluzzi et al., 2012). This mode may be activated by stress concentrations transferred to the substrate by stiff adhesive layers, which locally overload the strength of the substrate, inducing rapid damage propagation. The reduction of these peaks by redistributing the shear stresses over a larger bond area may lead to an increase of the overall shear strength of the system, as already demonstrated by former studies on highly deformable adhesives (Kwiecień, 2009; 2012; Derkowski et al., 2013), such as flexible polyurethane polymer PS (Kwiecień, 2012). The use of such kind of matrices to bond composite reinforcements to brittle substrates has recently proven its effectiveness in laboratory tests on small (Kwiecień and Zając, 2012; Kwiecień, 2013; 2014; 2015; Viskovic et al., 2015) and large scale (Kubica et al., 2008; Derkovski et al., 2013; Gams et al., 2014; 2015; Tedeschi et al., 2014) specimens, providing at the same time high ductility (Gams et al., 2015; Viskovic et al., 2015), good removability (Kwiecień, 2015) and thermal compatibility with masonry (Tedeschi et al., 2014; Zając and Kwiecień, 2014).

These advantageous properties of highly deformable adhesives were a base of an innovative repair solution that consists in reusing the detached composite reinforcement strip after failure and re-bonding it with flexible polyurethane polymer PS. This idea was first proposed by Kwiecień et al. (2012) and then further developed in laboratory tests (Kwiecień and Zając, 2015; Ghiassi et al., 2015). These studies showed that the use of a more deformable matrix than epoxy resin may provide a better stress redistribution over a bonded area, leading to good shear bond performance with promising perspectives for structural applications to weak and brittle substrates, such as masonry. The reuse of these reinforcements after failure could allow saving money, which may be particularly important when very large funds are required for rescue and restoration 
after catastrophic events. Furthermore, the polyurethane PS can be used, among others, as a quick protection and a repair method of failed (detached) composite strengthening systems just after first earthquake shock, protecting a weakened structure against collapse during an aftershock occurrence.

In order to gain an improved understanding on the structural effectiveness of this new repair method, a Round Robin Tests (named RRT3), was undertaken by five institutions: the Cracow university of Technology (CUT, Poland), the University of Bologna (UNBO, Italy), the University of Minho (UMINHO, Portugal), the University of Naples "Federico II" (UNINA, Italy), and Roma Tre University (UNIRM3. Italy) (Table 1). The research study was organized by the RILEM Technical Committee 250-CSM: Composites for the Sustainable strengthening of Masonry, within a wide experimental programme (started with a previous RILEM TC 223-MSC) that includes Round Robin Tests programmes on FRP/SRP systems bonded to clay bricks (RRT1, Valluzzi et al., 2012) and masonry (RRT2, de Felice et al., 2015a) substrates. Composite reinforcements comprising glass (GFRP), basalt (BFRP), carbon (CFRP) and steel (SRP) textiles were bonded to clay bricks and masonry prisms with epoxy resin. The specimens were tested within RRT2, then repaired by re-bonding detached reinforcements with a flexible polyurethane polymer PS and tested again within RRT3. The results of both investigations (RRT2 and RRT3) are compared in this paper in terms of ultimate loads, load-displacement curves and strain distributions to investigate the potentialities of the proposed repair method as an effective and cost efficient solution for the repair of damaged structures and their strengthening and protection against earthquakes.

\section{EXPERIMENTAL PROGRAMME AND SETUP}

\subsection{Repair methodology using highly deformable polyurethane polymer PS}

In the framework of RRT2, Single Lap Shear Tests (SLST) and Double Lap Shear Tests (DLST) were carried out on single bricks and masonry prism specimens, on which glass, basalt, carbon and steel textiles were bonded with epoxy resin (de Felice et al., 2015a). In most tests, failure on brick substrates occurred by cohesive debonding involving the substrate, with the detachment of a uniform thin layer of brick, which remained attached to the FRP strip along the whole bonded length. Differently, in case of masonry substrates, the failure surface was rougher, due to the presence of the mortar bed joints. After RRT2 tests, the specimens with the detached FRP strip in good conditions (Fig. 1a) were reused within RRT3. The failure surfaces were cleaned from loose particles using compressed air and impregnated by special primer for polyurethane adhesives (Fig. 1b). Then, the detached composites were bonded again to the substrate using flexible polyurethane adhesive of high deformability made of the polymer PS (Fig. 1b), so that the PS was glued between two surfaces of substrate. The thickness of the adhesive PS was rather variable, because of the roughness of the surfaces. Curing time of the polymer PS is 24 hours (producer data), and all the specimens were tested few months after repair. The repair application of the polymer PS at failure surfaces was done in 
the same manner in various laboratories by experts from CUT and local laboratory staff. On the whole 32 tests on bricks and 31 tests on masonry prisms were carried out (Table 1).

a)

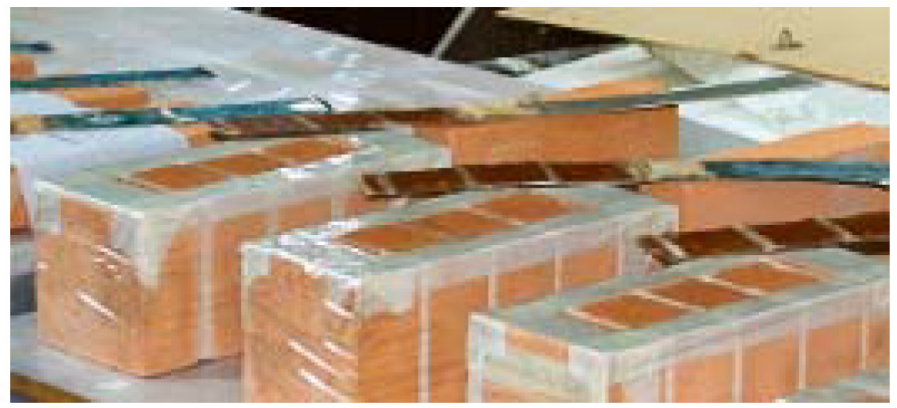

b)

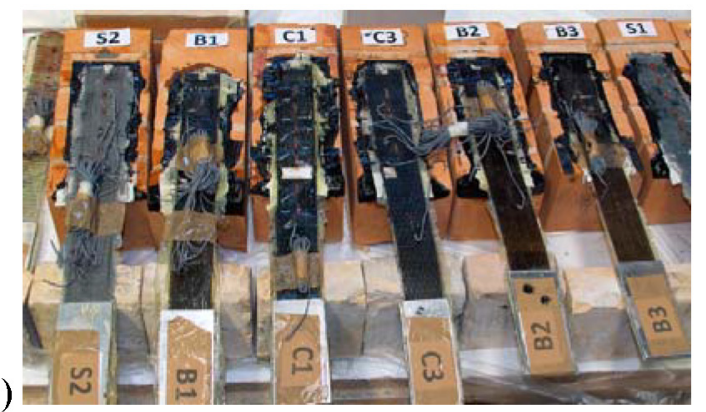

Figure 1 Prism specimens before repair (RRT2) (a) and after repair (RRT3) (b).

Table 1 Partner laboratories involved in RRT3.

\begin{tabular}{|c|c|c|c|c|c|c|c|c|c|c|}
\hline \multirow{2}{*}{ Institution name } & \multirow[b]{2}{*}{ Acronym } & \multirow{2}{*}{ Setup } & \multicolumn{4}{|c|}{ Brick specimens } & \multicolumn{4}{|c|}{ Masonry prism specimens } \\
\hline & & & GFRP & BFRP & CFRP & SRP & GFRP & BFRP & CFRP & SRP \\
\hline $\begin{array}{c}\text { Cracow University of } \\
\text { Technology }\end{array}$ & CUT & SLST & & & 5 & 5 & & & & \\
\hline University of Bologna & UNIBO & SLST & 3 & & 3 & 3 & 4 & & 2 & 1 \\
\hline University of Minho & UMINHO & SLST & 7 & & & & & & & \\
\hline $\begin{array}{c}\text { University of Naples } \\
\text { 'Federico II' }\end{array}$ & UNINA & DLST & 3 & 2 & 3 & 3 & 3 & 3 & 3 & 3 \\
\hline University of Roma Tre & UNIRM3 & SLST & & & & & 3 & 3 & 3 & 3 \\
\hline
\end{tabular}

\subsection{Properties of the materials}

Two types of bricks were used such as Portuguese bricks, with dimensions $200 \times 100 \times 50 \mathrm{~mm}^{3}$, used by UMINHO, and Italian bricks, with dimensions $250 \times 120 \times 55 \mathrm{~mm}^{3}$, used by CUT, UNIBO, UNINA and UNIRM3. As for the former ones, GFRP reinforcement was applied with epoxy resin MapeWrap 31, while the latter ones were tested with all textile materials (namely, basalt, carbon, glass and steel), bonded with either epoxy resin Sikadur 330 (CUT) or epoxy resin Saturant HM (UNIBO, UNINA). Masonry prisms were made out of five layers and four 10mm thick mortar joints (T30V Tassullo mortar was used). GFRP, BFRP, CFRP and SRP strips were bonded with epoxy resin Saturant HM (UNIBO, UNINA, UNIRM3). The mechanical properties of the materials are collected in Table 2 and more details on these investigations can be found in (Valluzzi et al., 2012; Panizza et al., 2012; Ghiassi et al., 2014; De Santis and de Felice, 2015). As for the matrices, the epoxy resins have tensile strength $\left(f_{\mathrm{tm}}\right)$ between 30 and $54 \mathrm{~N} / \mathrm{mm}^{2}$ and Young's modulus $\left(E_{\mathrm{tm}}\right)$ between 1300 and $4500 \mathrm{~N} / \mathrm{mm}^{2}$, while polymer PS has $f_{\mathrm{tm}}=2.87 \mathrm{~N} / \mathrm{mm}^{2}$ and $E_{\mathrm{tm}}=14.8 \mathrm{~N} / \mathrm{mm}^{2}$. These latter properties were obtained through tensile tests performed according to ISO 527-1 (2012), analyzed according to CUT procedure, carried out with a Zwick testing machine at the strain rate of $100 \% / \mathrm{min}$. 
Table 2 Mechanical properties of the tested materials.

\begin{tabular}{|c|c|c|c|}
\hline Masonry brick (Portugal $200 \times 100 \times 50 \mathrm{~mm}^{3}$ ) & & & $\operatorname{CoV}(\%)$ \\
\hline Compressive strength & $f_{\mathrm{cb}}(\mathrm{MPa})$ & 14.3 & 4.0 \\
\hline \multicolumn{4}{|l|}{ Masonry brick (Italy $250 \times 120 \times 55 \mathrm{~mm}^{3}$ ) } \\
\hline Compressive strength & $f_{\mathrm{cb}}(\mathrm{MPa})$ & 19.76 & 2.5 \\
\hline \multicolumn{4}{|l|}{ Mortar } \\
\hline Compressive strength & $f_{\mathrm{cb}}(\mathrm{MPa})$ & 2.62 & 10.9 \\
\hline \multicolumn{4}{|l|}{ Masonry prism (Italy $125 \times 120 \times 315 \mathrm{~mm}^{3}$ ) } \\
\hline Compressive strength & $f_{\mathrm{cb}}(\mathrm{MPa})$ & 8.24 & 20.9 \\
\hline \multicolumn{4}{|l|}{ GFRP coupons (Portugal) } \\
\hline Tensile strength & $f_{\mathrm{tf}}(\mathrm{MPa})$ & 1250 & 15.0 \\
\hline Elastic modulus & $E_{\mathrm{f}}(\mathrm{MPa})$ & 79200 & 6.8 \\
\hline Ultimate deformation & $\varepsilon(\%)$ & 3.0 & 20.2 \\
\hline \multicolumn{4}{|l|}{ GFRP coupons (Italy) } \\
\hline Tensile strength & $f_{\mathrm{tf}}(\mathrm{MPa})$ & 1141 & 12.1 \\
\hline Elastic modulus & $E_{\mathrm{f}}(\mathrm{MPa})$ & 80120 & 5.4 \\
\hline Ultimate deformation & $\varepsilon(\%)$ & 1.5 & 11.7 \\
\hline \multicolumn{4}{|l|}{ BFRP coupons (Italy) } \\
\hline Tensile strength & $f_{\mathrm{tf}}(\mathrm{MPa})$ & 1812 & 4.8 \\
\hline Elastic modulus & $E_{\mathrm{f}}(\mathrm{MPa})$ & 86830 & 3.7 \\
\hline Ultimate deformation & $\varepsilon(\%)$ & 2.2 & 5.8 \\
\hline \multicolumn{4}{|l|}{ CFRP coupons (Italy) } \\
\hline Tensile strength & $f_{\mathrm{tf}}(\mathrm{MPa})$ & 2889 & 7.8 \\
\hline Elastic modulus & $E_{\mathrm{f}}(\mathrm{MPa})$ & 241020 & 2.0 \\
\hline Ultimate deformation & $\varepsilon(\%)$ & 1.3 & 9.1 \\
\hline \multicolumn{4}{|l|}{ SRP coupons (Italy) } \\
\hline Tensile strength & $f_{\mathrm{tf}}(\mathrm{MPa})$ & 3050 & 6.3 \\
\hline Elastic modulus & $E_{\mathrm{f}}(\mathrm{MPa})$ & 200020 & 3.4 \\
\hline Ultimate deformation & $\varepsilon(\%)$ & 1.7 & 9.7 \\
\hline \multicolumn{4}{|l|}{ Epoxy resin (MapeWrap 31) } \\
\hline Tensile strength & $f_{\mathrm{tm}}(\mathrm{MPa})$ & 53.8 & 9.7 \\
\hline Elastic modulus & $E_{\mathrm{m}}(\mathrm{MPa})$ & 2500 & 9.5 \\
\hline \multicolumn{4}{|l|}{ Epoxy resin (Sikadur 330) } \\
\hline Tensile strength & $f_{\mathrm{tm}}(\mathrm{MPa})$ & 30 & (producer data) \\
\hline Elastic modulus & $E_{\mathrm{m}}(\mathrm{MPa})$ & 4500 & (producer data) \\
\hline \multicolumn{4}{|l|}{ Epoxy resin (Saturant HM) } \\
\hline Tensile strength & $f_{\mathrm{tm}}(\mathrm{MPa})$ & 32.7 & 8.0 \\
\hline Elastic modulus & $E_{\mathrm{m}}(\mathrm{MPa})$ & 1308 & 10.0 \\
\hline Polyurethane polymer (PS) & & & $\mathrm{CoV}(\%)$ \\
\hline Tensile strength & $f_{\mathrm{tm}}(\mathrm{MPa})$ & 2.87 & 2.2 \\
\hline Elastic modulus & $E_{\mathrm{m}}(\mathrm{MPa})$ & 14.8 & 12.6 \\
\hline
\end{tabular}

\subsection{Specimens and test setups}

The same specimens and the same test setup (which is specific of each individual laboratory) already used in RRT2 were also used in RRT3 to allow comparisons. The load was measured by either external or internal cells, the relative displacement between substrate and reinforcements (slip) was recorded at the loaded end of the bonded area (i.e., on the side where the external force was applied) by LVDTs, and, finally, the strain profile along the bonded area was recorded by resistive strain gauges. The minimum acquisition rate adopted was $5 \mathrm{~Hz}$, and tests were run under displacement control until complete failure (detachment or tensile rupture of composites) at $0.3 \mathrm{~mm} / \mathrm{min}$ rate. 
Tests were carried out using a Single Lap (SL) setup in CUT, UNIBO, UMINHO and UNIRM (Fig. 2a). More specifically, UMINHO, UNIBO and UNIRM3 used a rigid supporting steel frame (Valluzzi et al., 2012; Ghiassi et al., 2014; de Felice et al., 2015a; Mazzotti et al., 2012; 2015a; 2015b), while CUT used a hinged C-shaped steel frame (Valluzzi et al., 2012; Kwiecień, 2012). Differently, UNINA used a Double Lap (DL) setup (Fig. 2b) comprising a steel cylinder of diameter $110 \mathrm{~mm}$ and a hinged H-shaped steel frame (Valluzzi et al., 2012). In most cases, and on both brick and masonry substrates, the bonded length $\left(\mathrm{L}_{\mathrm{b}}\right)$ was $200 \mathrm{~mm}$, its width $\left(b_{\mathrm{f}}\right)$ was $50 \mathrm{~mm}$ and the distance from the loaded end of the bonded area and the edge of the substrate (c) was $30 \mathrm{~mm}$. Only in UMINHO, $\mathrm{L}_{b}=150 \mathrm{~mm}$ and $\mathrm{c}=40 \mathrm{~mm}$. On masonry substrate, the bonded length corresponded to three bricks and three mortar joints. In addition, two other bonded length values were investigated, such as $\mathrm{L}_{b}=65 \mathrm{~mm}$ and $\mathrm{L}_{b}=135 \mathrm{~mm}$, corresponding to one brick and one joint and to two bricks and two joints, respectively. In these cases, $c=55 \mathrm{~mm}$.

a)

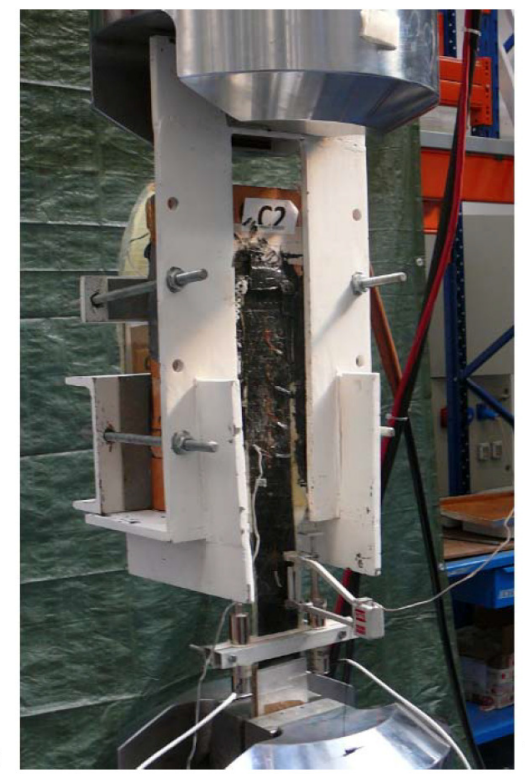

b)

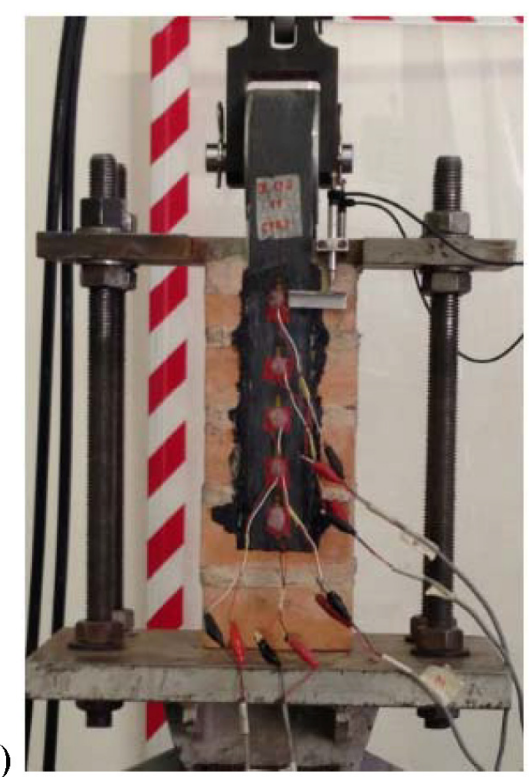

Figure 2 Testing setups: Single Lap Shear Test (SLST, a) and Double Lap Shear Test (DLST, b) schemes.

\section{RESULTS OF SHEAR BOND TESTS ON BRICK SUBSTRATE}

The analysis of the results and the comparison between RRT2 and RRT3 was carried out separately in 4 groups: SL_brick150, SL_brick200S, SL_brick200, DL110_brick200, which were different in the type of the brick (Portuguese/Italian), the bond length (150mm/200mm), and the epoxy resin (M31/S330/HM). Table 3 collects the failure loads $\left(F_{\max }\right)$ of individual specimens, and the average value $\left(F_{\text {mean }}\right)$ and the coefficient of variation $(\mathrm{CoV})$ of the test series. The strengthening ratio is evaluated as $F_{\max }$ after repair (polymer PS) divided by $F_{\max }$ before repair (epoxy) for each individual pair of specimens and on average for each test series as well. Finally, the failure mode is indicated by letters A-F according to the following list: A: cohesive debonding with the detachment of a uniform thin layer of the substrate; B: cohesive debonding with the detachment of a non-uniform thick layer of the substrate; C: fiber rupture; D: cohesive failure in the 
adhesive layer; E: breaking of the substrate; F: strip debonding on resin side, while polymer PS was on the other side (DL tests).

\subsection{Single Lap shear bond tests}

Within RRT2, Single Lap shear tests were carried out on GFRP bonded to Portuguese bricks for a length of $\mathrm{L}_{\mathrm{b}}=150 \mathrm{~mm}$ with epoxy M31 at UMINHO. This test series is named SL_brick150. The maximum load ( $\left.F_{\text {mean }}\right)$ was $7.93 \mathrm{kN}$ and all specimens failed by cohesive debonding (mode A). After repair with highly deformable polymer PS (RRT3), the strength increased to $12.57 \mathrm{kN}$ (1.6 times higher than with resin, on average) and failure occurred by cohesive debonding with the detachment of either a uniform thin (mode A) or nonuniform thick (B) layer of the substrate, or also within the thickness of the adhesive layer (D). Carbon and steel textiles were bonded on Italian bricks with epoxy S330 for a bonded length of $200 \mathrm{~mm}$ and tested in CUT (SL_brick200S). The failure loads were, on average, $7.03 \mathrm{kN}$ for CFRP and $6.78 \mathrm{kN}$ for SRP and increased to $9.36 \mathrm{kN}$ and $13.37 \mathrm{kN}$ after repair. Failure always occurred by debonding in the substrate (mode A) with epoxy adhesive, while modes B and D also occurred with the polymer. A brick broke during a test on CFRP during RRT3. GFRP, CFRP and SRP were bonded with HM resin and tested in UNIBO. Also in this test series (SL_brick200) the failure loads increased by 1.1-1.2 times after repair with polymer, passing from $5.2 \mathrm{kN}$ to $6.18 \mathrm{kN}$ for glass, from $8.19 \mathrm{kN}$ to $8.98 \mathrm{kN}$ for carbon and, finally, from $7.96 \mathrm{kN}$ to $9.74 \mathrm{kN}$ for steel. In all these specimens, failure mode A occurred in RRT2 while mode B occurred in RRT3.

\subsection{Double Lap shear bond tests}

Double Lap shear bond tests were carried out in UNINA on GFRP. BFRP, CFRP and SRP. The reinforcements were bonded to the bricks using HM epoxy in RRT2 for a bonded length of $200 \mathrm{~mm}$. This test series was named DL110_brick200, 110 standing for the diameter of the cylinder used in the setup. In RRT2, only one side failed and was then repaired using polymer PS, while the other side remained without visible damage. As in Single Lap tests, both an increase of the maximum load and a modification of the failure mode occurred after repair with polymer PS (RRT3) with respect to the former tests with epoxy resin (RRT2). Strength values ranged from $4.50 \mathrm{kN}$ for glass to $6.70 \mathrm{kN}$ for steel reinforcements and increased by 1.04-1.69 times after re-bonding. Cohesive debonding was observed in all tests carried out within RRT2, while mode $\mathrm{C}$ (fiber rupture in the unbonded portion) and mode $\mathrm{F}$ (strip debonding on resin side) also occurred in RRT3.

\subsection{Comparison of results}

All the test series carried out on brick substrates, including different bricks, epoxy resins and reinforcement textiles, displayed higher failure loads after repair polymer PS than with epoxy resin. The strengthening ratios were always higher than 1 and varied in the range 1.04-2.01, proving the effectiveness of the proposed repair solution. The failure modes A, B and D observed in specimens repaired with polymer PS indicate that the repair joint fully exploited the material strength of the substrate and/or of the repairing matrix. On the 
other hand, the occurrence of failure modes $\mathrm{C}, \mathrm{E}$ and $\mathrm{F}$ suggests that the strengthening ratios in these cases may be lower than the maximum exploitable ones, because the specimens did not utilize the whole bond capacity after repair. If the strips had not ruptured or debonded on the resin side (while polymer PS was on the other side) and the tested bricks had not broken, higher values of ultimate force could have been probably obtained. Therefore, in these specimens, the bond with polymer PS is not the weakest element of the system.

In addition to such strength increase, the comparison of the load-slip curves (Fig. 3) shows that the specimens after repair are more deformable than before repair, thanks to the lower Young's modulus of the polymer PS and its capability to reduce stress concentrations in the substrate, especially when it is weakened after failure, which is particularly important for perspective applications to damaged structures. In curves obtained during RRT2, the presence of a nearly flat branch before failure is associated to the activation and progressive development of the debonding process along the bonded area. This happens when the bonded area is longer than the effective bond length, which is defined as that allowing for the exploitation of the whole bond strength (an increase of the bond length over the effective one does not lead to an increase of the maximum load). On the contrary, the absence of this nearly flat branch in the curves recorded during RRT3 suggests that the effective bond length with the polymer PS is longer than $200 \mathrm{~mm}$. Finally, while the RRT2 curves are nearly superimposed, the RRT3 ones present a larger scatter, even if derived in the same laboratory, which may be due to variability of the substrate surface failed in RRT2 and repaired with the polymer as well as of the thickness of the layer of the polymer PS. 
Table 3 Results of shear bond tests on brick substrates.

\begin{tabular}{|c|c|c|c|c|c|c|c|c|c|}
\hline SL_brick150 & & & $F_{\max }(\mathbf{k N})$ & & & & & $F_{\text {mean }}(\mathbf{k N})$ & $\operatorname{CoV}(\%)$ \\
\hline GFRP_UM & G1 & G2 & G3 & G4 & G5 & G6 & G7 & & \\
\hline ероху М31 & $8.96^{\mathrm{A}}$ & $7.13^{\mathrm{A}}$ & $7.41^{\mathrm{A}}$ & $7.43^{\mathrm{A}}$ & $7.70^{\mathrm{A}}$ & $9.36^{\mathrm{A}}$ & $7.51^{\mathrm{A}}$ & 7.93 & 10.9 \\
\hline polymer PS & $15.45^{\mathrm{D}}$ & $12.04^{\mathrm{B}}$ & $12.45^{\mathrm{B}}$ & $11.42^{\mathrm{A}}$ & $12.32^{\mathrm{D}}$ & $11.01^{\mathrm{B}}$ & $13.30^{\mathrm{B}}$ & 12.57 & 11.7 \\
\hline strengthening ratio (-) & 1.72 & 1.69 & 1.68 & 1.54 & 1.60 & 1.18 & 1.77 & 1.60 & 12.5 \\
\hline \multicolumn{10}{|l|}{ SL_brick200S } \\
\hline CFRP_CUT & C1 & $\mathrm{C2}$ & C3 & $\mathrm{C4}$ & $\mathbf{C 5}$ & & & & \\
\hline epoxy S330 & $6.32^{\mathrm{A}}$ & $7.71^{\mathrm{A}}$ & $8.85^{\mathrm{A}}$ & $6.05^{\mathrm{A}}$ & $6.23^{\mathrm{A}}$ & & & 7.03 & 17.2 \\
\hline polymer PS & $9.23^{\mathrm{B}}$ & $8.45^{\mathrm{E}}$ & $8.97^{\mathrm{B}}$ & $11.02^{\mathrm{D}}$ & $9.14^{\mathrm{D}}$ & & & 9.36 & 10.4 \\
\hline strengthening ratio (-) & 1.46 & 1.10 & 1.01 & 1.82 & 1.47 & & & 1.37 & 23.7 \\
\hline SRP_CUT & S1 & $\mathbf{S 2}$ & S3 & S4 & S5 & & & & \\
\hline epoxy S330 & $6.66^{\mathrm{A}}$ & $5.76^{\mathrm{A}}$ & $6.91^{\mathrm{A}}$ & $7.02^{\mathrm{A}}$ & $7.53^{\mathrm{A}}$ & & & 6.78 & 9.6 \\
\hline polymer PS & $15.08^{\mathrm{B}}$ & $16.31^{\mathrm{B}}$ & $13.99^{\mathrm{B}}$ & $8.49^{\mathrm{B}}$ & $13.00^{\mathrm{B}}$ & & & 13.37 & 22.4 \\
\hline strengthening ratio (-) & 2.27 & 2.83 & 2.02 & 1.21 & 1.73 & & & 2.01 & 30.0 \\
\hline \multicolumn{10}{|l|}{ SL_brick200 } \\
\hline GFRP_BO & G1 & G2 & G3 & & & & & & \\
\hline ероху $\overline{\mathrm{HM}}$ & $5.27^{\mathrm{A}}$ & $5.10^{\mathrm{A}}$ & $5.30^{\mathrm{A}}$ & & & & & 5.22 & 2.0 \\
\hline polymer PS & $6.21^{\mathrm{B}}$ & $5.86^{\mathrm{B}}$ & $6.46^{\mathrm{B}}$ & & & & & 6.18 & 4.9 \\
\hline strengthening ratio (-) & 1.18 & 1.15 & 1.22 & & & & & 1.18 & 3.0 \\
\hline CFRP_BO & C1 & $\mathrm{C} 2$ & C3 & & & & & & \\
\hline epoxy HM & $8.93^{\mathrm{A}}$ & $7.74^{\mathrm{A}}$ & $7.90^{\mathrm{A}}$ & & & & & 8.19 & 7.9 \\
\hline polymer PS & $7.04^{\mathrm{B}}$ & $8.34^{\mathrm{B}}$ & $11.55^{\mathrm{B}}$ & & & & & 8.98 & 25.8 \\
\hline strengthening ratio (-) & 0.79 & 1.08 & 1.46 & & & & & 1.11 & 30.3 \\
\hline SRP_BO & S1 & $\mathbf{S 2}$ & S3 & & & & & & \\
\hline ероху НM & $7.00^{\mathrm{A}}$ & $8.60^{\mathrm{A}}$ & $8.29^{\mathrm{A}}$ & & & & & 7.96 & 10.6 \\
\hline polymer PS & $8.40^{\mathrm{B}}$ & $12.73^{\mathrm{B}}$ & $8.10^{\mathrm{B}}$ & & & & & 9.74 & 26.6 \\
\hline strengthening ratio (-) & 1.20 & 1.48 & 0.98 & & & & & 1.22 & 20.5 \\
\hline \multicolumn{10}{|l|}{ DL110_brick200 } \\
\hline GFRP_NA & G1 & G2 & G3 & & & & & & \\
\hline epoxy HM & $4.03^{\mathrm{A}}$ & $5.00^{\mathrm{A}}$ & $4.47^{\mathrm{A}}$ & & & & & 4.50 & 10.8 \\
\hline polymer PS & $5.01^{\mathrm{C}}$ & $5.99^{\mathrm{C}}$ & $4.98^{\mathrm{F}}$ & & & & & 5.33 & 10.8 \\
\hline strengthening ratio (-) & 1.24 & 1.20 & 1.11 & & & & & 1.18 & 5.6 \\
\hline BFRP_NA & B1 & B2 & & & & & & & \\
\hline ероху $\overline{\mathrm{HM}}$ & $4.74^{\mathrm{A}}$ & $4.71^{\mathrm{A}}$ & & & & & & 4.72 & 0.5 \\
\hline polymer PS & $9.85^{\mathrm{C}}$ & $4.87^{\mathrm{F}}$ & & & & & & 7.36 & 47.8 \\
\hline strengthening ratio (-) & 2.08 & 1.04 & - & & & & & 1.56 & 47.1 \\
\hline CFRP_NA & C1 & $\mathbf{C 2}$ & C3 & & & & & & \\
\hline ероху $\overline{\mathrm{HM}}$ & $6.53^{\mathrm{A}}$ & $6.75^{\mathrm{A}}$ & $6.61^{\mathrm{A}}$ & & & & & 6.63 & 1.6 \\
\hline polymer PS & $10.32^{\mathrm{A}}$ & $12.12^{\mathrm{C}}$ & $11.18^{\mathrm{A}}$ & & & & & 11.21 & 8.0 \\
\hline strengthening ratio (-) & 1.58 & 1.80 & 1.69 & & & & & 1.69 & 6.5 \\
\hline SRP_NA & S1 & $\mathbf{S 2}$ & S3 & & & & & & \\
\hline ероху HM & $6.93^{\mathrm{A}}$ & $7.92^{\mathrm{A}}$ & $7.96^{\mathrm{A}}$ & & & & & 7.60 & 7.6 \\
\hline polymer PS & $8.79^{\mathrm{F}}$ & $7.33^{\mathrm{F}}$ & $7.38^{\mathrm{F}}$ & & & & & 7.83 & 10.5 \\
\hline strengthening ratio (-) & 1.27 & 0.93 & 0.93 & & & & & 1.04 & 18.8 \\
\hline
\end{tabular}

${ }^{\mathrm{A}}$ Cohesive debonding with the detachment of a uniform thin layer of the substrate

${ }^{\mathrm{B}}$ Cohesive debonding with the detachment of a non-uniform thick layer of the substrate

${ }^{\mathrm{C}}$ Fiber rupture

${ }^{\mathrm{D}}$ cohesive failure in the adhesive layer

${ }^{\mathrm{E}}$ breaking of the substrate

${ }^{\mathrm{F}}$ Strip debonding on resin side, while polymer PS was on the other side (DL tests) 

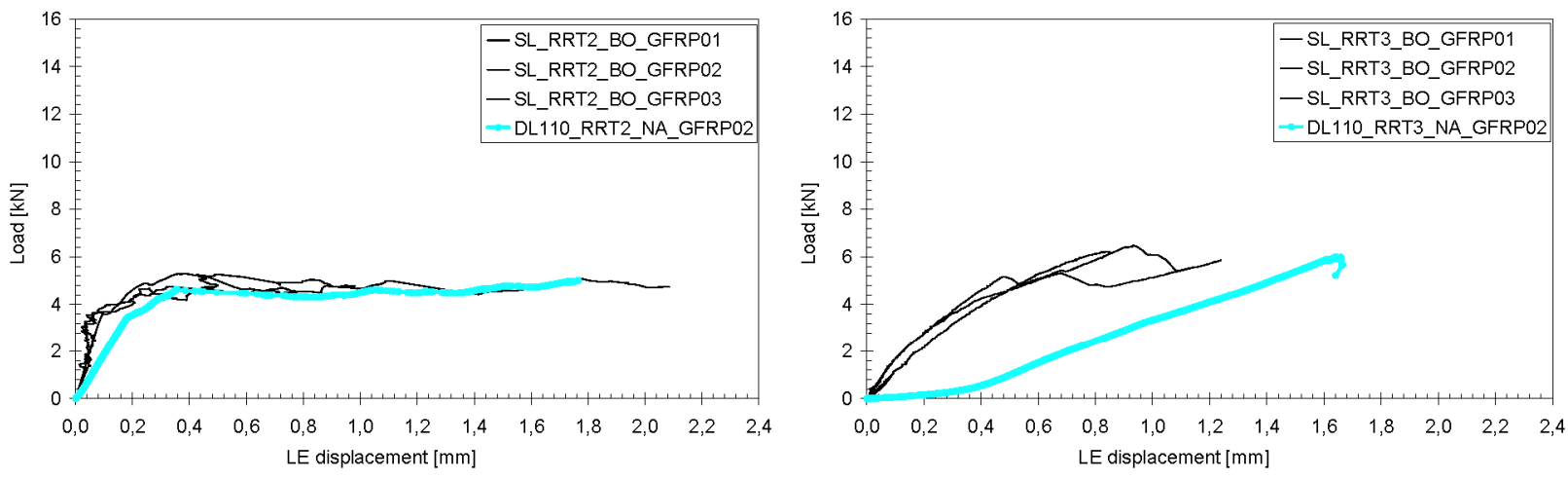

a)
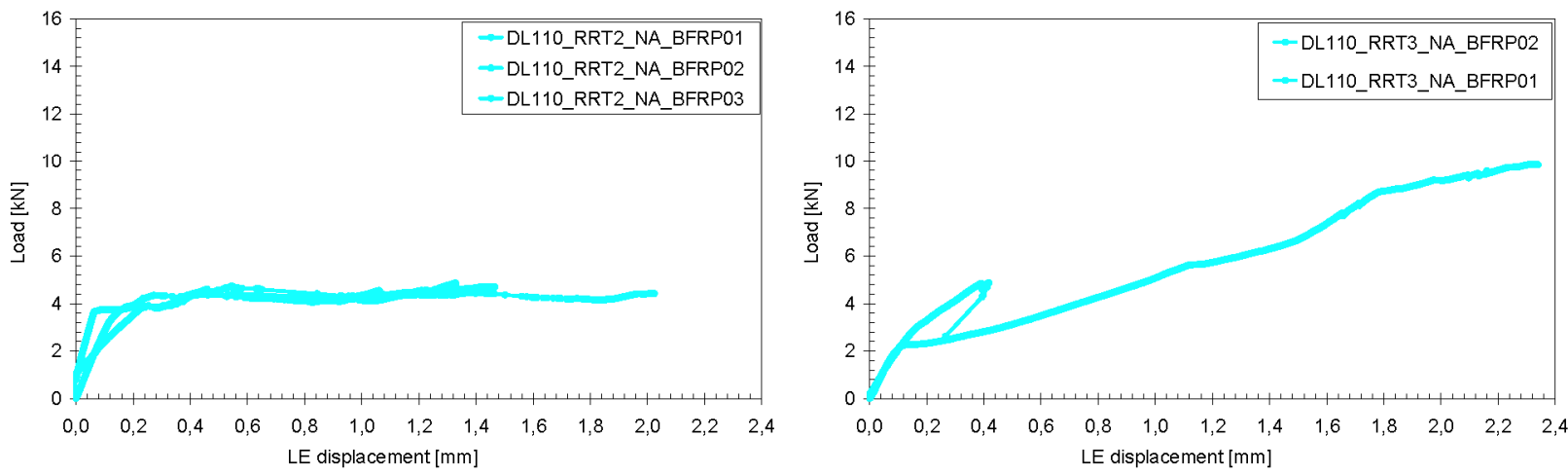

b)
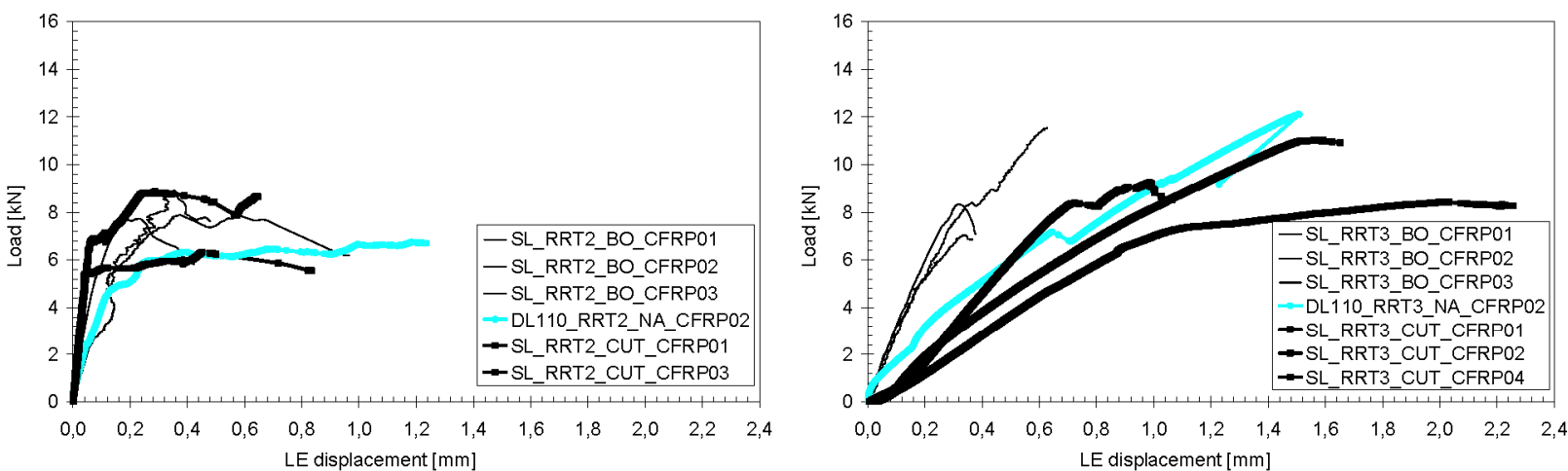

c)
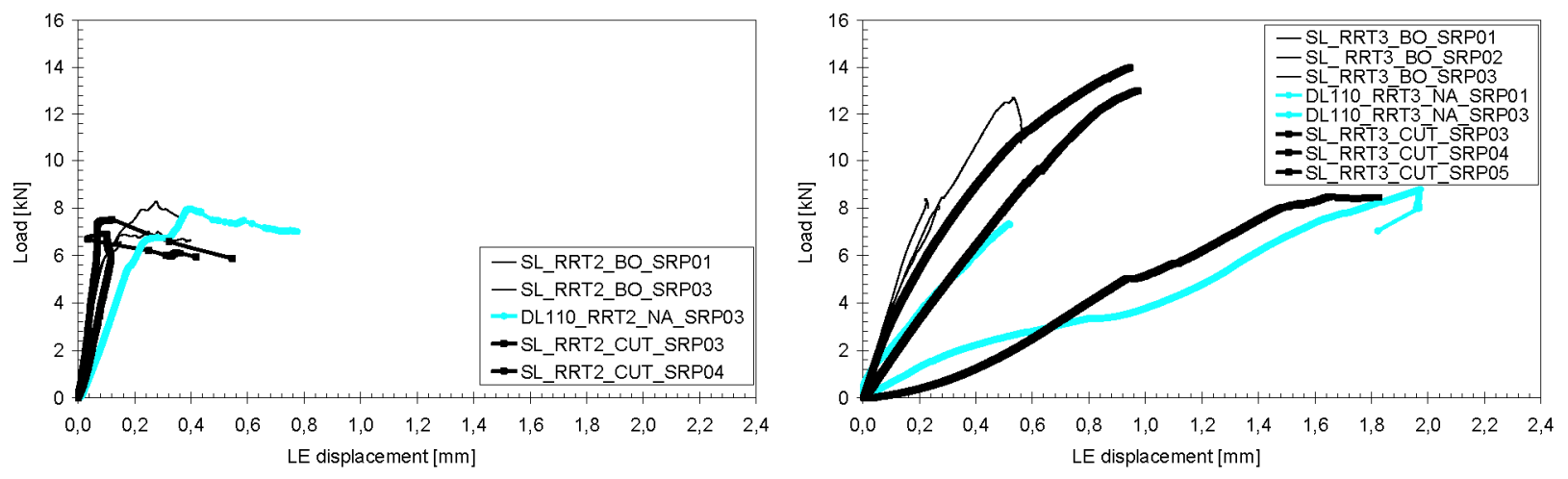

Figure 3 Load-slip curves of shear bond tests on brick substrates before (RRT2 - left) and after (RRT3 - right) repair:

GFRP (a), BFRP (b), CFRP (c) and SRP (d). 


\section{RESULTS OF SHEAR BOND TESTS ON MASONRY SUBSTRATE}

Shear bond tests were carried out with carbon, basalt, glass and steel reinforcements bonded to brick masonry prisms. Both Single Lap and Double Lap setups were used, and the resulting load-slip curves are shown in Figure 4, while Table 4 collects the outcomes of all tests: failure loads of individual specimens $\left(F_{\max }\right)$, average values $\left(F_{\text {mean }}\right)$ and coefficients of variation $(\mathrm{CoV})$ for each test series, strengthening ratios and failure modes (A-F) according to the same nomenclature described in the previous section.

\subsection{Single Lap shear bond tests}

Single Lap tests were performed at UNIBO and UNIRM3. During RRT2, the reinforcements were bonded using epoxy resin HM for a bonded length of $200 \mathrm{~mm}$. The average failure loads were $7.08 \mathrm{kN}$ for GFRP, $7.52 \mathrm{kN}$ for BFRP, $10.12 \mathrm{kN}$ for CFRP and, finally, $9.53 \mathrm{kN}$ for SRP. Failure occurred by cohesive debonding within the substrate (mode A) independently from the textile material. After re-bonding with highly deformable polymer PS, the shear bond strength increased to $8.47 \mathrm{kN}$ for glass, $9.77 \mathrm{kN}$ for basalt, $12.81 \mathrm{kN}$ for carbon and $14.56 \mathrm{kN}$ for steel reinforcements, with strengthening ratios ranging from 1.26 (GFRP) to 1.55 (SRP). Failure mode B occurred in most cases, but some specimens with glass reinforcement displayed the tensile rupture of the textile (mode C). Shorter bond lengths of the GFRP reinforcements were also tested (G6 and G7 specimens in Table 4). The former $\left(\mathrm{L}_{b}=135 \mathrm{~mm}\right)$ was in good agreement with other results (the strengthening ratio was 1.48$)$, while the latter $\left(\mathrm{L}_{b}=65 \mathrm{~mm}\right)$ was the only test in which the strength after rebonding was lower than that found with epoxy resin, because such bonded length was larger than the effective one for epoxy resin but too short for the polymer.

\subsection{Double Lap shear bond tests}

Double Lap tests were carried out in UNINA on all reinforcement types. As for brick substrates, only one side failed and was then repaired using polymer PS, while the other side remained without visible damage. In RRT2, failure loads ranged between 4.53kN (BFRP) and 9.38kN (SRP) and failure mode A occurred. After repair, the shear bond strength increased by 1.17(SRP)-1.62(BFRP) times and different failure modes were activated including mode $\mathrm{C}$ (fiber rupture, with the weakest textile), mode $\mathrm{F}$ (strip debonding on resin side), and, in one case of SRP, mode B (cohesive debonding with the detachment of a non-uniform thick layer of the substrate) (Table 4).

\subsection{Comparison of results on masonry substrate}

Similarly to the tests on brick substrates, the shear bond performance of FRP reinforcements on brickwork increased after repair with polymer PS. The average strengthening ratios were always larger than 1 and ranged between 1.18 and 1.63 (Fig. 6), provided that the bonded length is not too short. These results prove the effectiveness of reusing detached composite strengthening systems by re-bonding them with the highly deformable polymer PS. The comparisons in terms of load-slip curves (Figs. 4 and 5), confirm the more deformable behavior of the repaired reinforcement if compared to that exhibited before repair, confirming 
the conclusions already found on bricks. Finally, also in this case, the effective bond length with the highly deformable polymer appears longer than $200 \mathrm{~mm}$. The RRT2 curves obtained from various laboratories are similar and almost overlapping (Fig. 4). In the case of the RRT3 curves, no significant differences in the bond strength of repaired masonry prisms were found between laboratories, but curves differ in stiffness from each other, especially between laboratories, due to the variability of the substrate surface and of the thickness of the polymer PS layer. Such scatter is larger than that found on bricks. In the case of masonry specimens, the repair surface is rougher than for bricks, because of missing parts due to previous failure (e.g. brick edges, mortar grooves), all filled/repaired by the polymer PS. The thicker layer of the polymer PS (e.g., of curves obtained by UNIRM3 if compared to those of UNIBO) results in higher deformability of the repair bond.

Table 4 Results of shear bond tests on masonry substrate.

\begin{tabular}{|c|c|c|c|c|c|c|c|c|c|}
\hline \multirow{2}{*}{$\begin{array}{c}\text { SL_prism200 } \\
\text { GFRP_RM3/BO }\end{array}$} & \multicolumn{7}{|c|}{$F_{\max }(\mathbf{k N})$} & \multirow[t]{2}{*}{$F_{\text {mean }}(\mathrm{kN})$} & \multirow[t]{2}{*}{$\operatorname{CoV}(\%)$} \\
\hline & G1 & G2 & G3 & G4 & G5 & $\boldsymbol{G \sigma}^{(1)}$ & $G \boldsymbol{7}^{(2)}$ & & \\
\hline epoxy HM & $9.10^{\mathrm{A}}$ & $7.77^{\mathrm{A}}$ & $6.81^{\mathrm{A}}$ & $4.7 \overline{7}^{\mathrm{A}}$ & $6.93^{\mathrm{A}}$ & $5.27^{\mathrm{A}}$ & $5.65^{\mathrm{A}}$ & 7.08 & 22.3 \\
\hline polymer PS & $8.88^{\mathrm{C}}$ & $7.14^{\mathrm{B}}$ & $8.24^{\mathrm{C}}$ & $9.10^{\mathrm{C}}$ & $9.01^{\mathrm{C}}$ & $7.82^{\mathrm{C}}$ & $4.72^{\mathrm{B}}$ & 8.47 & 9.6 \\
\hline strengthening ratio (-) & 0.98 & 0.92 & 1.21 & 1.91 & 1.30 & 1.48 & 0.83 & 1.26 & 31.2 \\
\hline BFRP_RM3 & B1 & B2 & B3 & & & & & & \\
\hline epoxy HM & $7.46^{\mathrm{A}}$ & $7.98^{\mathrm{A}}$ & $7.11^{\mathrm{A}}$ & & & & & 7.52 & 5.8 \\
\hline polymer PS & $8.77^{\mathrm{D}}$ & $9.07^{\mathrm{B}}$ & $11.46^{\mathrm{B}}$ & & & & & 9.77 & 15.1 \\
\hline strengthening ratio (-) & 1.18 & 1.14 & 1.61 & & & & & 1.31 & 19.9 \\
\hline CFRP_RM3/BO & C1 & $\mathrm{C} 2$ & C3 & $C 4$ & C5 & & & & \\
\hline epoxy HM & $12.85^{\mathrm{A}}$ & $8.72^{\mathrm{A}}$ & $10.68^{\mathrm{A}}$ & $9.19^{\mathrm{A}}$ & $9.18^{\mathrm{A}}$ & & & 10.12 & 16.7 \\
\hline polymer PS & $12.69^{\mathrm{B}}$ & $11.95^{\mathrm{D}}$ & $11.97^{\mathrm{B}}$ & $12.29^{\mathrm{B}}$ & $15.13^{\mathrm{B}}$ & & & 12.81 & 10.4 \\
\hline strengthening ratio (-) & 0.99 & 1.37 & 1.12 & 1.34 & 1.65 & & & 1.29 & 19.6 \\
\hline SRP_RM3/BO & S1 & S2 & S3 & $S 4$ & & & & & \\
\hline epoxy HM & $9.10^{\mathrm{A}}$ & $11.72^{\mathrm{A}}$ & $9.12^{\mathrm{A}}$ & $8.18^{\mathrm{A}}$ & & & & 9.53 & 16.0 \\
\hline polymer PS & $15.24^{\mathrm{B}}$ & $14.70^{\mathrm{B}}$ & $14.04^{\mathrm{B}}$ & $14.24^{\mathrm{B}}$ & & & & 14.56 & 3.7 \\
\hline strengthening ratio (-) & 1.67 & 1.25 & 1.54 & 1.74 & & & & 1.55 & 14.0 \\
\hline \multicolumn{10}{|l|}{ DL120_prism200 } \\
\hline GFRP_NA & G1 & G2 & G3 & & & & & & \\
\hline epoxy HM & $4.90^{\mathrm{A}}$ & $4.15^{\mathrm{A}}$ & $5.55^{\mathrm{A}}$ & & & & & 4.87 & 14.3 \\
\hline polymer PS & $6.73^{\mathrm{C}}$ & $6.10^{\mathrm{A}}$ & $8.63^{\mathrm{C}}$ & & & & & 7.15 & 18.4 \\
\hline strengthening ratio (-) & 1.37 & 1.47 & 1.56 & & & & & 1.47 & 6.5 \\
\hline BFRP_NA & B1 & B2 & B3 & & & & & & \\
\hline epoxy HM & $4.11^{\mathrm{A}}$ & $4.62^{\mathrm{A}}$ & $4.86^{\mathrm{A}}$ & & & & & 4.53 & 8.5 \\
\hline polymer PS & $6.43^{\mathrm{F}}$ & $5.86^{\mathrm{F}}$ & $9.87^{\mathrm{A}}$ & & & & & 7.39 & 29.4 \\
\hline strengthening ratio (-) & 1.56 & 1.27 & 2.03 & & & & & 1.62 & 23.7 \\
\hline CFRP_NA & C1 & $\mathrm{C2}$ & $\mathbf{C 3}$ & & & & & & \\
\hline epoxy HM & $7.84^{\mathrm{A}}$ & $7.01^{\mathrm{A}}$ & $7.24^{\mathrm{A}}$ & & & & & 7.37 & 5.8 \\
\hline polymer PS & $9.00^{\mathrm{F}}$ & $6.91^{\mathrm{C}}$ & $11.85^{\mathrm{B}}$ & & & & & 9.26 & 26.8 \\
\hline strengthening ratio (-) & 1.15 & 0.99 & 1.64 & & & & & 1.26 & 26.9 \\
\hline SRP_NA & S1 & $\mathbf{S 2}$ & S3 & & & & & & \\
\hline ероху HM & $9.41^{\mathrm{A}}$ & $9.76^{\mathrm{A}}$ & $8.98^{\mathrm{A}}$ & & & & & 9.38 & 4.2 \\
\hline polymer PS & $9.47^{\mathrm{F}}$ & $14.80^{\mathrm{B}}$ & $8.84^{\mathrm{F}}$ & & & & & 11.04 & 29.7 \\
\hline strengthening ratio (-) & 1.01 & 1.52 & 0.98 & & & & & 1.17 & 25.9 \\
\hline $\begin{array}{l}\text { A Cohesive debonding } \\
{ }^{\mathrm{B}} \text { Cohesive debonding } \\
{ }^{\mathrm{C}} \text { Fiber rupture } \\
{ }^{\mathrm{D}} \text { Cohesive failure in } \mathrm{t} \\
{ }^{\mathrm{E}} \text { Breaking of the subs } \\
{ }^{\mathrm{F}} \text { Strip debonding on } \mathrm{r} \\
{ }^{(1)} \mathrm{L}_{b}=135 \mathrm{~mm} \text { (exclude } \\
{ }^{(2)} \mathrm{L}_{b}=65 \mathrm{~mm} \text { (excluded }\end{array}$ & $\begin{array}{l}\text { with the } \\
\text { with the } \\
\text { e adhesi } \\
\text { rate } \\
\text { sin side, } \\
\text { from th } \\
\text { from the }\end{array}$ & $\begin{array}{l}\text { letachme } \\
\text { letachme } \\
\text { e layer } \\
\text { while pol } \\
\text { evaluati } \\
\text { evaluatio }\end{array}$ & $\begin{array}{l}\text { ner PS } \\
\text { of me } \\
\text { of mea }\end{array}$ & $\begin{array}{l}\text { as on the } \\
\text { and } \mathrm{Co} \\
\text { and } \mathrm{CoV}\end{array}$ & $\begin{array}{l}\text { other sid } \\
\text { values) } \\
\text { values) }\end{array}$ & $\begin{array}{l}\text { e subst } \\
\text { of the }\end{array}$ & $\begin{array}{l}\text { ate } \\
\text { ubstr }\end{array}$ & & \\
\hline
\end{tabular}



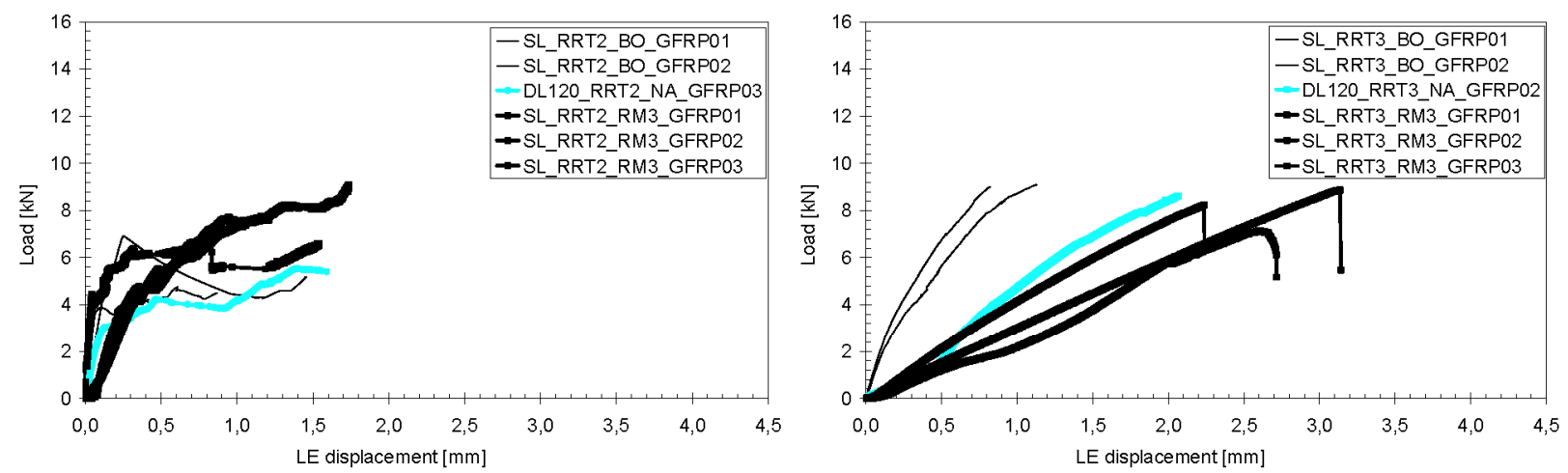

a)

LE displacement [mm]
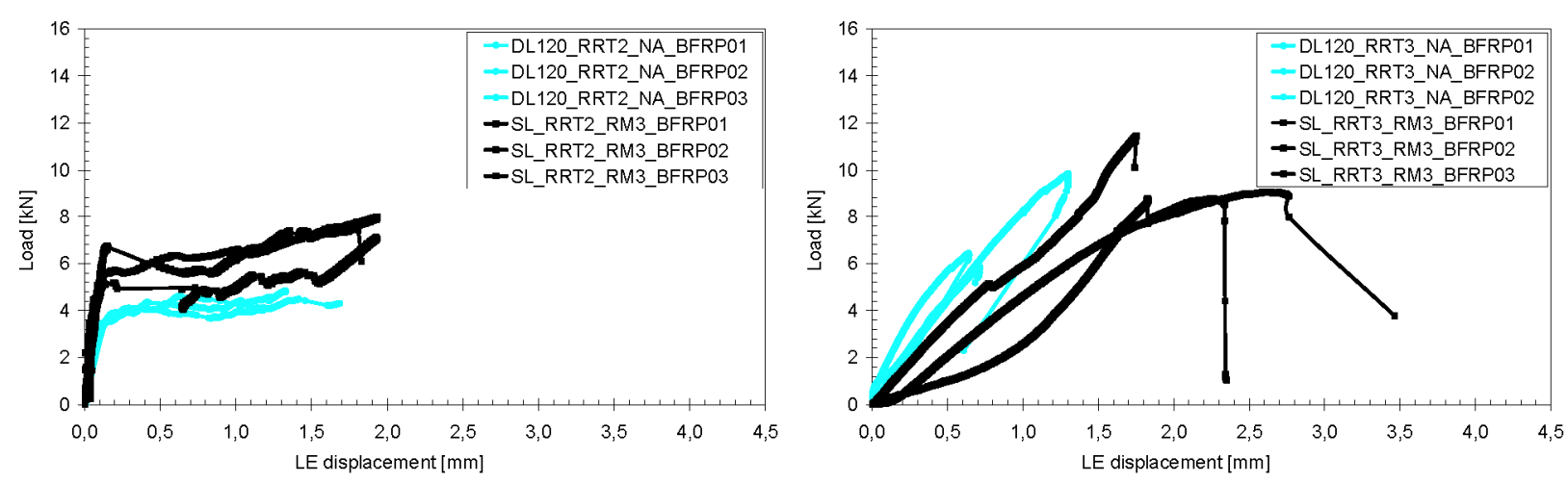

b)

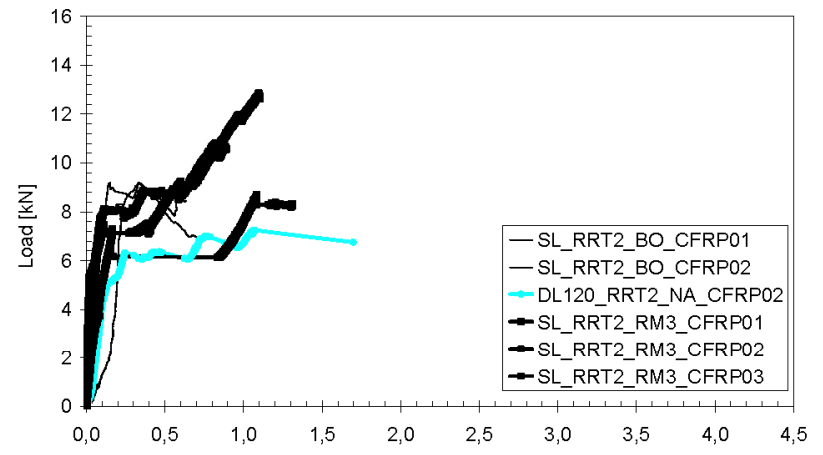

c)

LE displacement [mm]
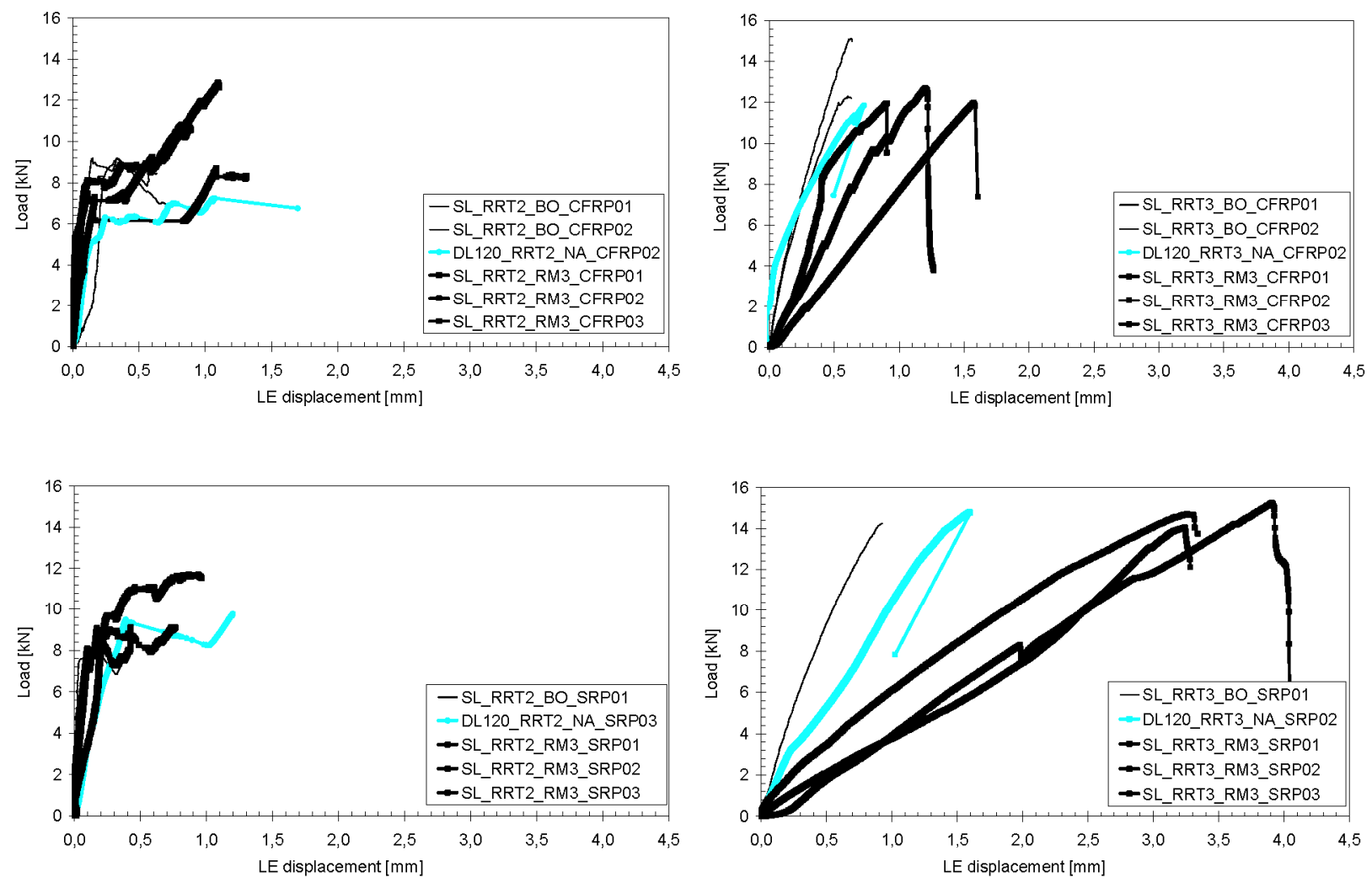

Figure 4 Load-slip curves of shear bond tests on masonry substrates before (RRT2 - left) and after (RRT3 - right) repair: GFRP (a), BFRP (b), CFRP (c) and SRP (d). 

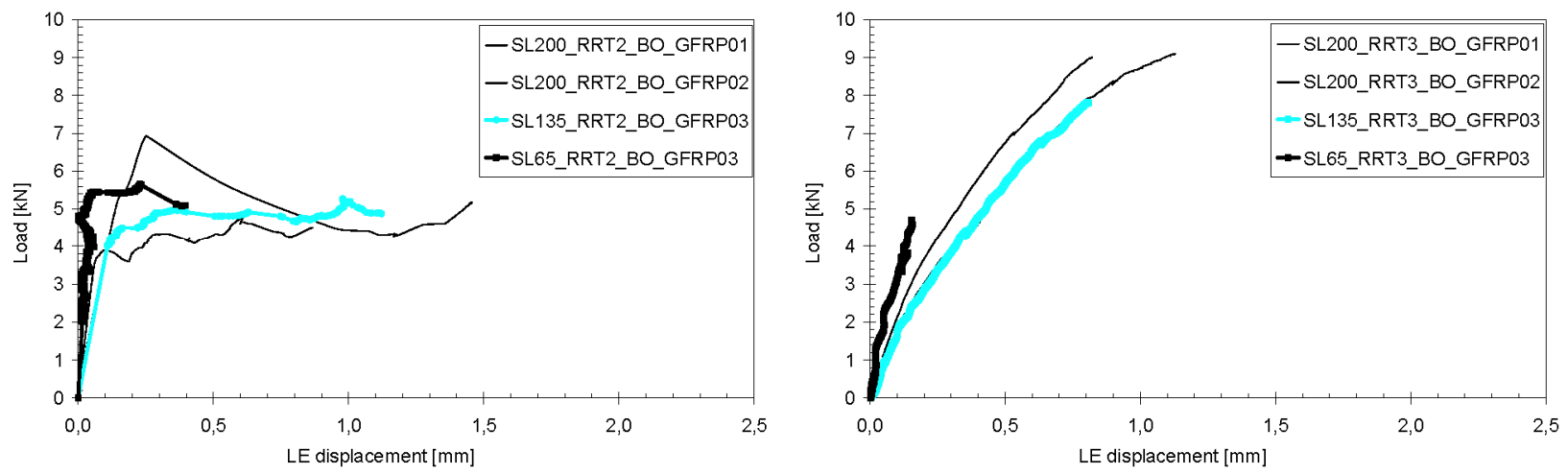

Figure 5 Load-slip curves of prism specimens before (RRT2 - left) and after (RRT3 - right) repair, for GFRP specimens with bond length of $65 \mathrm{~mm}, 135 \mathrm{~mm}$, and $200 \mathrm{~mm}$
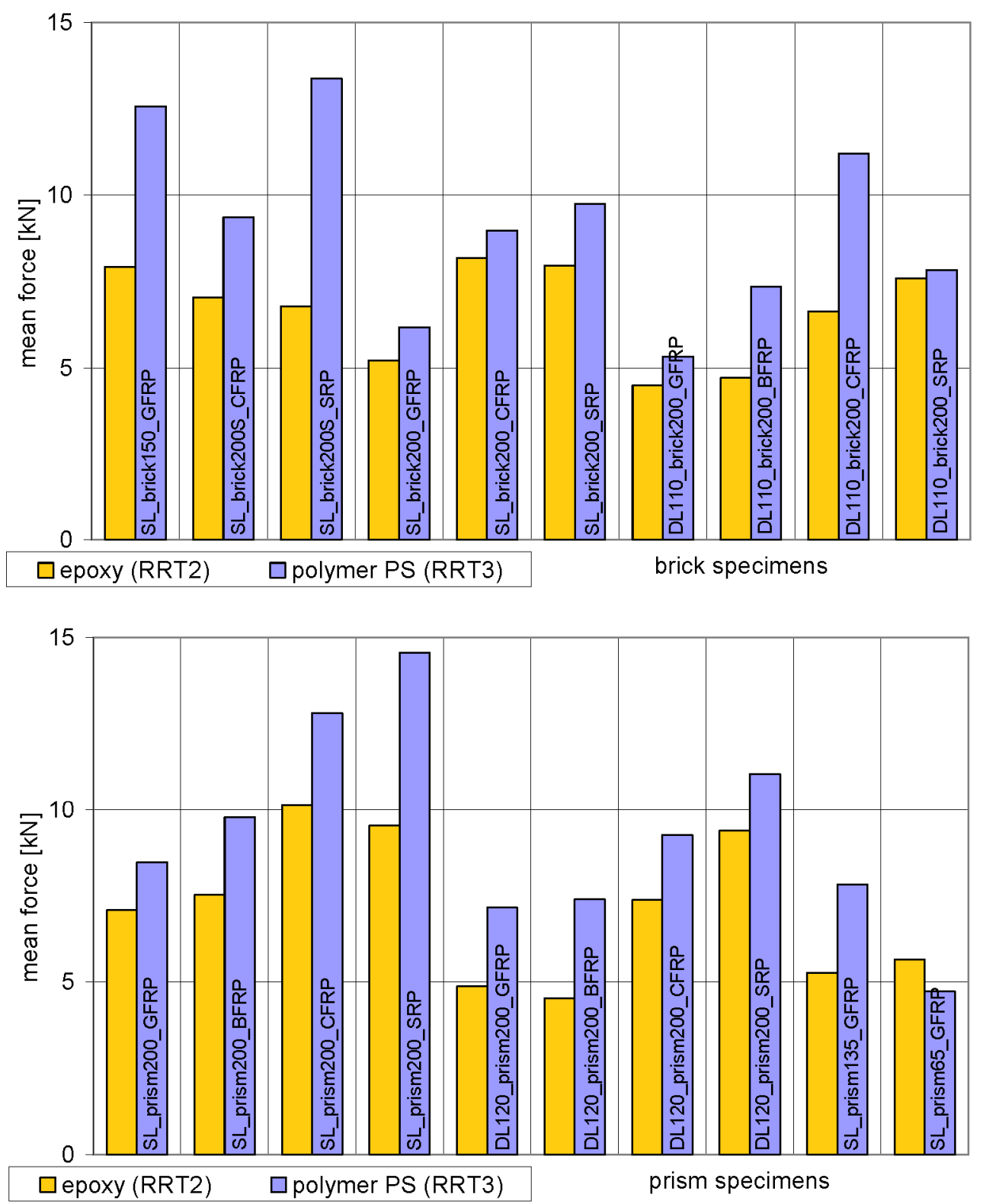

Figure 6 Comparison of mean ultimate loads before and after repair obtained on brick and masonry substrates. 


\section{STRAIN DISTRIBUTIONS}

The strain in the reinforcements was measured along the bonded area using resistive strain gauges. The comparison of strain distributions between RRT2 and RRT3 is shown in Fig. 7 for bricks and in Fig. 8 for masonry, for pairs of the same specimens (before and after repair) and for 5 levels of load, ranging from $20 \%$ to $100 \%$ of $F_{\max }$. In these plots, the distance from the unloaded end of the bonded area (opposite to the side of load application) is on the x-axis. Therefore, the value at position $200 \mathrm{~mm}$ represents the strain in the unbonded textile, which was either recorded by a strain gauge or derived as the load divided by the cross section area of the reinforcement and its Young's modulus.

The strain profiles of RRT2 manifested an exponential shape until the failure load, with a high gradient (that is, there is a steep increase of strain in the vicinity of the loaded end, at least for relatively low load values, Fig. 7). By looking at the change of the concavity of the strain profiles, the effective bond length can be estimated to be $60-70 \mathrm{~mm}$ for GFRP and of about $80 \mathrm{~mm}$ for CFRP and, 170-190mm for SRP (no data were available for basalt) (de Felice et al., 2015a). At the activation and progressive development of the debonding process, a rapid increase of strains was observed along the bonded length. The same brick specimens, repaired using the highly deformable polymer PS (RRT3), also manifested the exponential shape of the strain distribution until the failure load, but with a lower gradient (that is, the curves are almost linear). The profiles suggest that the effective bond length is longer than $200 \mathrm{~mm}$, independently from the textile material, because continuous and proportional increase of strains was recorded by all strain gauges on the whole bonded region during the development of the debonding process without any clear change of the concavity of the curves. The comparison of the strain distributions of RRT2 and RRT3 for the brick specimens also shows that after repair the strain values increased over the whole bonded area, which started deforming without strain the concentrations that were responsible for the rapid detachment of the reinforcement strip when applied with epoxy resin. This more efficient stress distribution led to the observed increase of the ultimate load.

The strain profiles of GFRP, BFRP, CFRP and SRP composites bonded to the masonry substrate are shown in Fig. 8. When the epoxy adhesive was used (RRT2) the curves manifested the same exponential shape discussed previously until the failure load, with high gradient of change. The effective bond length values were similar to those estimated in the case of the brick specimens and a rapid increase of strains was also observed along the bonded length during the development of the debonding process. The same prism specimens, repaired using the highly deformable polymer PS (RRT3), also displayed an exponential shape of the strain distribution but with lower gradient. Continuous and proportional increase of strains was recorded by all strain gauges on the whole bonded region, as the debonding process was developing, especially in the middle of the bonded length (Fig. 8c), and the effective bond length was therefore estimated to be longer than $200 \mathrm{~mm}$ (significantly increased than before repair) 

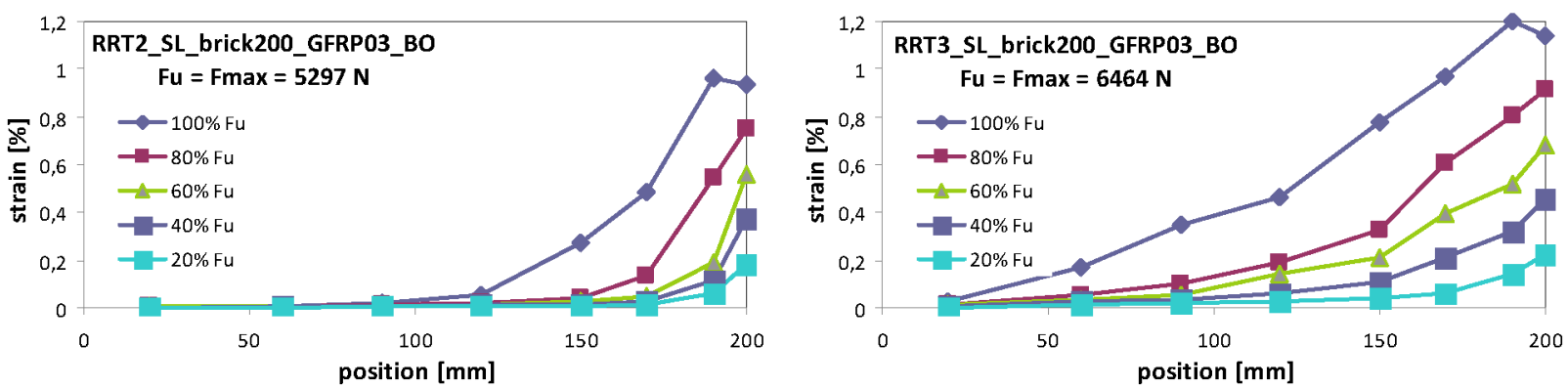

a)
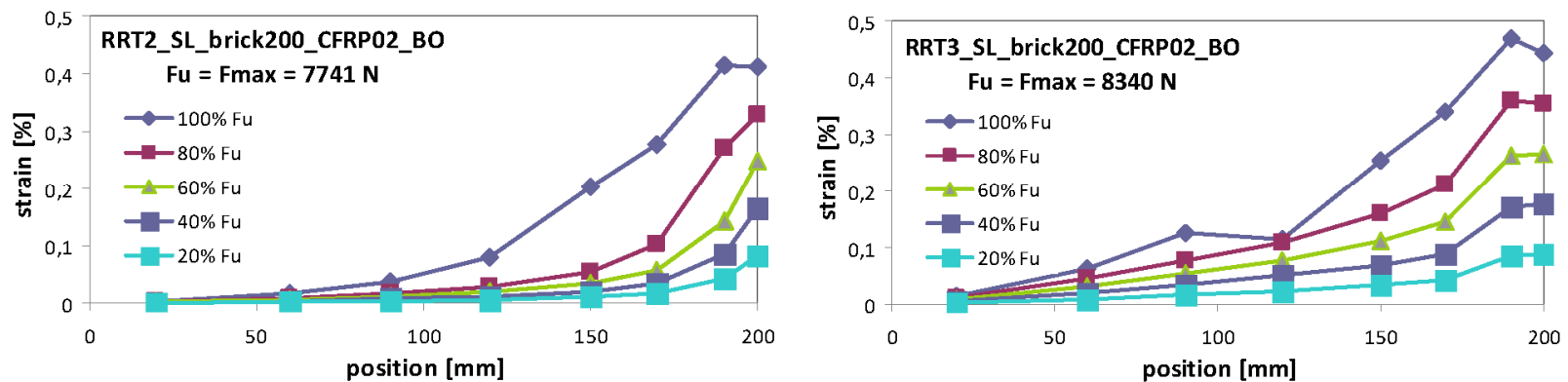

b)
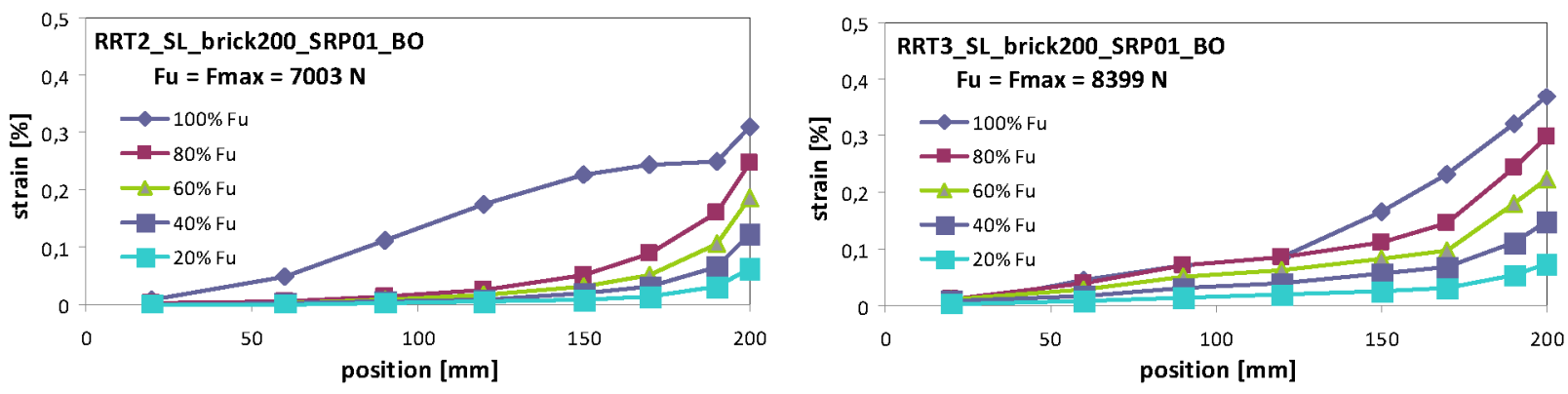

c)

Figure 7 Strain distribution along the bonded area on brick substrates before (RRT2 - left) and after (RRT3 - right):

GFRP (a), CFRP (b) and SRP (c). 

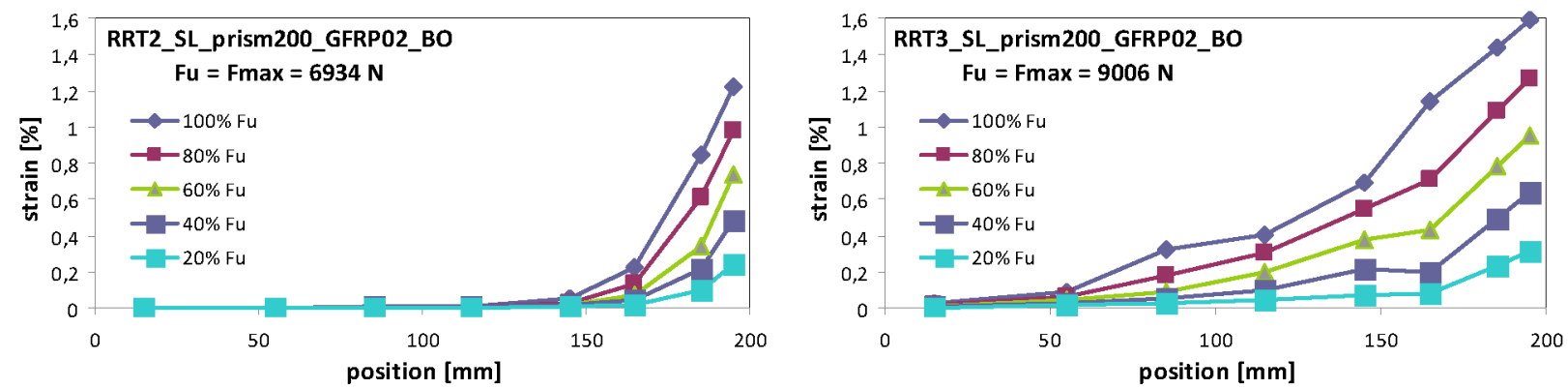

a)
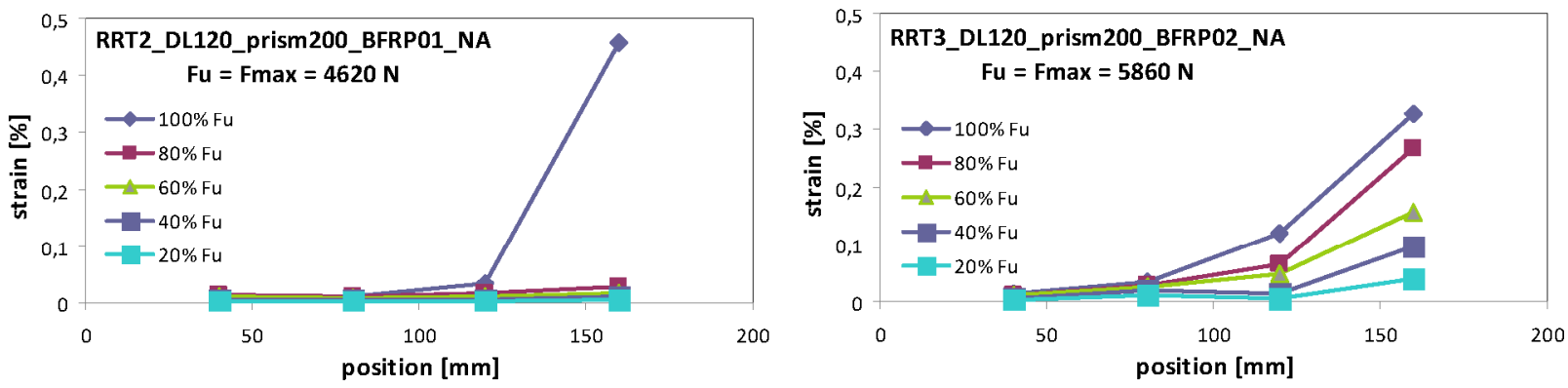

b)
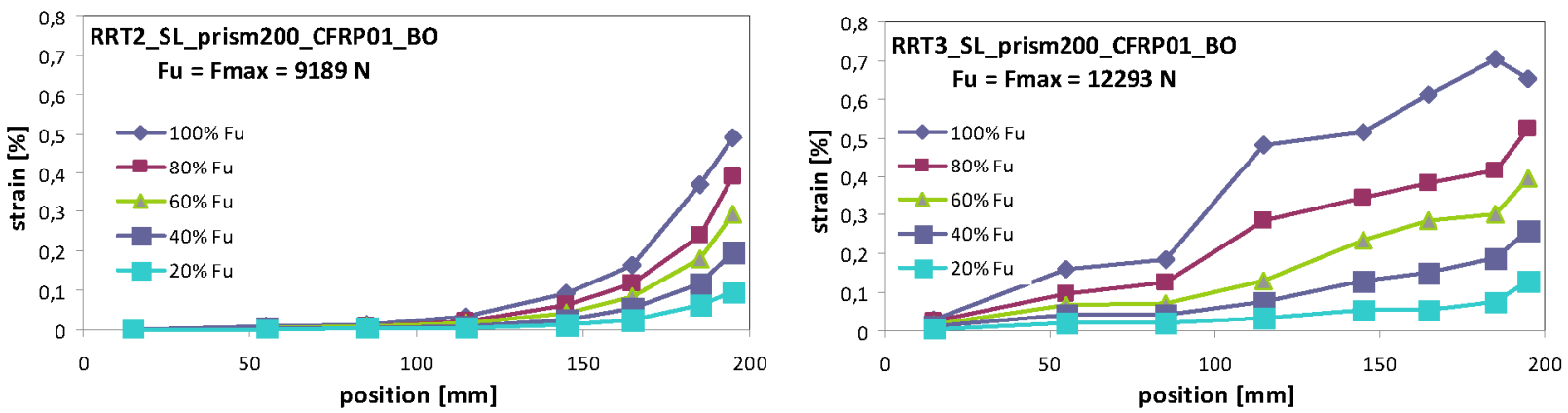

c)
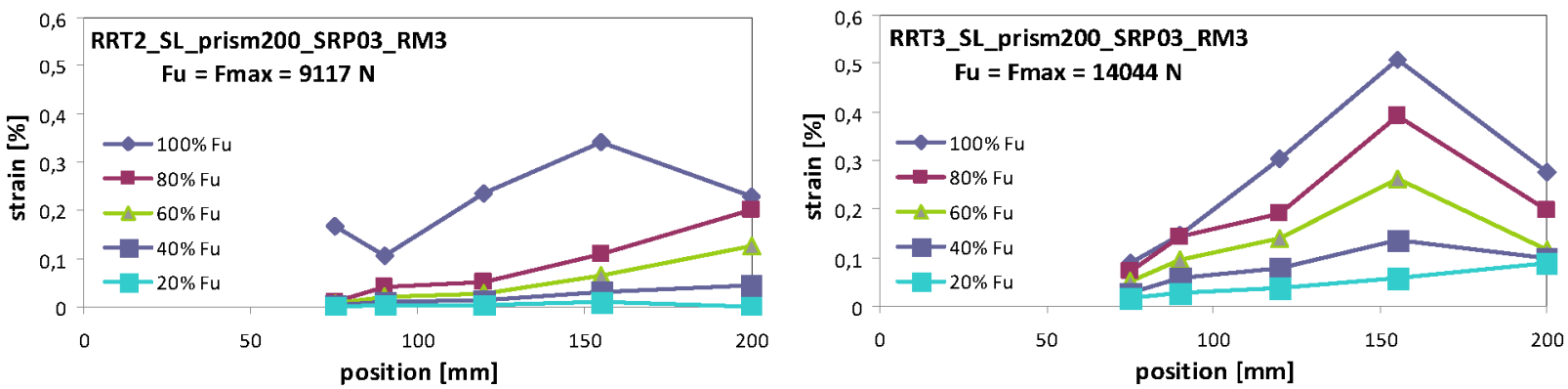

Figure 8 Strain distribution along the bonded area on masonry substrates before (RRT2 - left) and after (RRT3 - right):

GFRP (a), BFRP (b), CRP (c), SFRP (d).

\section{PERSPECTIVE STRUCTURAL APPLICATIONS OF THE PROPOSED REPAIR METHOD}

Externally bonded reinforcement with composite materials has become a popular solution for repairing and retrofitting existing masonry structures, but may be inefficient in some applications to weak and brittle substrates. Mineral mortars and polymeric resins, traditionally used to apply externally bonded reinforcements, may generate high stress under large deformations and have a relatively short bonded length due to their high stiffness. Larger bonding areas would do not provide any increase of the ultimate strength, 
because local stress concentration initiate the reinforcement detachment at relatively low load levels. Beyond this point, a small increase of the load would still be possible (caused mainly by an interlocking effect) and pseudo-ductile behavior could be observed. This pseudo-ductility is however practically inefficient, because it covers only the damage process and takes a short time before detachment. As a consequence, the actual exploitation of the tensile strength of reinforcement is often relatively low (in the order of $20 \%-30 \%$ ) such that in the case of debonding failure the reinforcement textile is not significantly damaged and, if re-bonded, would still be able to carry design loads with sufficient residual safety level.

The weakest point in the composites-to-masonry systems is generally the brittle masonry substrate (especially in masonry of low strength). It has been observed that when the peaks of the shear stress overcome the strength of the substrate, a weak zone generates, which is full of micro-cracks that, in their turn, induce the development of major delaminating cracks and, eventually, cause the detachment of the composite strips with a thin layer of masonry substrate. The reuse of these reinforcements after detachment could allow saving money, which may be particularly important when very large funds are required for rescue and restoration after catastrophic events. A repair of such failure zone (re-bonding together the detached elements) with the same epoxy resin is however fraught with a risk that the weakened microcracked zone is unable to carry the same level of load as the ultimate one before repair, because high levels of stress concentration may be generated again, which are unable to withstand by the failure zone of the brittle substrate, weakened by existing micro-cracks (Kwiecień, 2013, Kwiecień and Zając, 2015).

The experiments presented in this paper allowed comparing the behavior up to failure of the brick and prism specimens reinforced with composite strips (GFRP, BFRP, CFRP and SRP) bonded by 3 epoxy adhesives of high stiffness $\left(E_{\mathrm{m}}=1308 \div 4500 \mathrm{~N} / \mathrm{mm}^{2}\right)$ and of high strength $\left(f_{\mathrm{tm}}=30.0 \div 53.8 \mathrm{~N} / \mathrm{mm}^{2}\right)$, with the same specimens repaired after failure using a highly deformable polyurethane polymer PS of low stiffness $\left(E_{\mathrm{m}}=14.8 \mathrm{~N} / \mathrm{mm}^{2}\right)$ and of low strength $\left(f_{\mathrm{tm}}=2.87 \mathrm{~N} / \mathrm{mm}^{2}\right)$. All specimens (both bricks and masonry prisms) after repair demonstrated higher average values of maximum load, and at higher displacements, than the same specimens tested before repair. These results confirmed the effectiveness of the proposed repair solution using the polymer PS adhesive, whose stiffness is several hundred times lower and whose strength is over a dozen times lower than originally used epoxy adhesives.

The highly deformable polymer PS adhesive assures reduction of stress concentration and more uniform strain redistribution in the repair bond, involving a larger bonded area than stiff epoxy adhesives. These properties are particularly important in joining of disrupted brittle structural elements, where weakening bonded surfaces are weakened by micro-cracks. Involving a larger bonded area with lower strain levels allows the bond to carry higher loads, ensuring that the safety level of the repaired structure is at least the equal to that before damage occurred in the externally bonded reinforcement system.

Application of the flexible polymer PS as the repair adhesive caused reduction of the bond stiffness only about 10 times, which is advantageous in repair application, where stress redistribution and ductile behavior 
is required. More flexible behavior of the repair adhesive assures many times a higher stored energy during the structure deformation. The comparison of the areas under load-displacement curves (up to the load level when the elastic behavior is lost) shows that with epoxy adhesive the bond may be strongly damaged such that only non-recovering dissipation energy would be available under cyclic loading. On the contrary, with highly deformable adhesive an additional amount of energy is stored, which may represent a safety reserve of the repaired structure. This ability could be especially advantageous in repair of structures in seismic areas (Gams et al., 2014).

\section{CONCLUSIONS}

The effectiveness of an innovative repair method that makes use of flexible polyurethane polymer PS to rebond detached composite reinforcements to the masonry substrate was investigated To this purpose, two Round Robin Tests series were organized by the RILEM TC 250-CSM involving five laboratories from Italy, Poland and Portugal. Shear bond tests were carried out on specimens strengthened with GFRP (glass), BFRP (basalt), CFRP (carbon) and SRP (steel) composites, which were first tested with epoxy adhesive, then repaired by re-bonding the detached reinforcement strips with polymer PS and tested again. Test results showed that the proposed repair method offers important advantages for several structural applications.

First, the shear bond strength is higher than that achieved with epoxy, on average by 1.1-2 times on brick substrates and 1.2-1.7 times on masonry substrates, thanks to the capability of the polyurethane polymer PS to redistribute the shear stresses over the bonded area, avoiding the local concentrations that may activate the debonding process. The strain profiles indicated a longer effective anchorage length (with respect to traditional FRPs), and even longer than that used for tests $(200 \mathrm{~mm})$, which in its turn may potentially provide a further increase of ultimate load strength.

Second, the reinforcement-to-substrate with the PS matrix is much more deformable than that with epoxy resin, which indicates that larger ductility and energy dissipation could be expected under cyclic loading. This aspect has not been investigated yet and represents one of the open issues needing further research.

Finally, the application of this flexible adhesive is rapid and does not require smooth surface of substrates, and, thanks to the short curing duration (material starts curing in 10-15 minutes after application and is able to carry loads just after 1-2 hours), the polyurethane PS can be used as a quick protection and a repair method for detached composite strengthening systems just after first earthquake shock, allowing protecting the weakened/damaged structure against collapse during an aftershock occurrence. Depper investigations (e.g., shake table testing) would provide a better understanding on the potentialities of this repair method for the seismic protection of existing structures. Also, since polyurethane adhesives have viscoelasto-plastic behaviour, future investigations on both rheological properties and durability are still needed before the proposed repair solution can be confidently used in field applications. Finally, analytical relationships need 
to be developed to estimate the shear bond strength of composite reinforcements bonded with highly deformable polymers and the performance of the reinforced structural members, in order to provide practicing engineers with reliable design criteria.

\section{ACKNOWLEDGMENTS}

Authors wish to thank M. Wojciechowski and M. Zając (CUT) for their contribution to prepare of specimens for testing. San Marco-Terreal Italian, Noale (Venice, Italy), Fidia Technical Global Service Perugia (Italy), Sika Poland Kraków supplied the materials for the preparation of the specimens.

\section{REFERENCES}

Ascione L, de Felice G, De Santis S. A qualification method for externally bonded Fibre Reinforced Cementitious Matrix (FRCM) reinforcement systems. Composites: Part B. DOI: 10.1016/j.compositesb.2015.03.079

Celestini G, Casadei P (2009) Innovation on Advanced Composite Materials for Strengthening and Protection of Historical Masonry Structures. In: Proc. of 3rd Conf. on Mechanics of masonry structures strengthened with composite materials: modeling, testing, design, control - MuRiCo3, Venice, Italy.

Ceroni F, de Felice G, Grande E, Malena M, Mazzotti C, Murgo F, Sacco E, Valluzzi MR (2014) Analytical and numerical modeling of composite-to-brick bond. Materials and Structures 47: 1987-2003.

Corradi M, Grazini A, Borri A (2007) Confinement of brick masonry columns with CFRP materials. Composites Science and Technology, 67 (9): 1772-1783.

de Felice G, Bellini A, Ceroni F, De Santis S, Garbin E, Leone M, Lignola GP, Malena M, Micelli F, Mazzotti C, Panizza M, Valluzzi MR (2015a). Experimental characterization of composite-to-brick masonry shear bond. Submitted.

de Felice G, De Santis S, Napoli A, Realfonzo R (2015b) Overview of the experimental works on steel reinforced polymer systems. 2nd International Symposium on Advances in Civil and infrastructure Engineerin. Vietri sul Mare, Italy. To appear.

De Santis S, De Canio G, de Felice G, Malena M, Mongelli M. Roselli I (2015) Seismic performance of masonry walls retrofitted with steel reinforced grout. Submitted.

De Santis S, de Felice G (2015) Tensile behaviour of mortar-based composites for externally bonded reinforcement systems. Composites: Part B, 68: 401-413.

De Santis S, de Felice G. Steel reinforced grout systems for the strengthening of existing structures. Submitted.

Derkowski W, Kwiecień A, Zając B (2013) CFRP strengthening of bent RC elements using stiff and flexible adhesives. Technical Transactions 1-B/2013: 37-52.

Flaga K, Kwiecień A (2010) Efficiency of CFRP strengthening of arches tested by failure of historical building after the inappropriate repair intervention. Advanced Materials Research, 133-134: 837-842.

Gams M, Kwiecień A, Zając B, Tomaževič M (2014) Seismic strengthening of brick masonry walls with flexible polymer coating. In: proc 9th International Masonry Conference, Guimarães, Portugal.

Gams M, Tomaževič M, Kwiecień A (2015) Strengthening brick masonry by repointing - an experimental study. Key Engineering Materials, 624: 444-452. 
Ghiassi B, Verstrynge E, Lourenço PB, Oliveira DV (2014) Characterization of debonding in FRPstrengthened masonry using the acoustic emission technique. Engineering Structures, 66: 24-34.

Ghiassi B, Xavier J, Oliveira DV, Kwiecień A, Lourenço PB, Zając B (2015) Evaluation of the bond performance in FRP-brick components re-bonded after initial delamination. Composite Structures, 123: 271-281.

Giamundo V, Lignola GP, Maddaloni G, Balsamo A, Prota A, Manfredi G (2015) Experimental investigation of the seismic performances of IMG reinforcement on curved masonry elements. Composites: Part B, 70: 53-63.

ISO 527-1. Plastics-determination of tensile properties- Part 1: general principles. 2012.

Jasieńko J, Bednarz Ł, Nowak T (2009) The effectiveness of strengthening historic brick vaults by contemporary methods. In: Proc. Protection of Historical Buildings Conference, PROHITECH2009, Taylor and Francis Group, Rome, Italy.

Kubica J, Kwiecień A, Zając B (2008) Repair and strengthening by use of superficial fixed laminates of cracked masonry walls sheared horizontally - laboratory tests. In: AIP Conf. Proc. 1020, 1546 (2008); Proc. of Seismic Engineering International Conference MERCEA'08, Villa San Giovanni Reggio Calabria, Italy.

Kwiecień A (2009) Polymer flexible joint-an innovative repair system protecting cracked masonries against stress concentrations. In: Proc. Protection of Historical Buildings Conference, PROHITECH2009, Taylor and Francis Group, Rome, Italy.

Kwiecień A (2012) Stiff and flexible adhesives bonding CFRP to masonry substrates - investigated in pulloff test and Single-Lap test. Archives of Civil and Mechanical Engineering, 12 (2): 228-239.

Kwiecień A (2013) Highly deformable polymers for repair and strengthening of cracked masonry structures. GSTF International Journal of Engineering Technology (JET 2013), 2 (1): 182-196.

Kwiecień A (2014) Shear bond of composites-to-brick applied with highly deformable, in relation to resin epoxy, interface materials. Materials and Structures, 47: 2005-2020.

Kwiecień A (2015) Strengthening of masonry using natural fibers bonding with highly deformable adhesives. GSTF Journal of Engineering Technology (JET 2015) 3 (2). In press.

Kwiecień A, Zając B (2012) Energy approach in analysis of masonry columns confined with GFRP mesh bonded on stiff and flexible adhesives. Structural Analysis of Historical Constructions - Jerzy Jasieńko (ed), DWE Wrocław, Poland, pp. 1864-1872.

Kwiecień A, Zając B (2015) Is it Possible to Repair Detached Composites Effectively after Failure of Masonry Strengthening? Key Engineering Materials, 624: 518-525.

Kwiecień A, Zając B, Kuboń P (2012) Post failure repair of strengthening system made of CFRP and GFRP strips bonded to brick substrate - examined in single-lap tests. In: Proc. 6th International Conference on FRP Composites in Civil Engineering CICE2012, Rome, Italy.

Lignola GP, Prota A, Manfredi G (2009) Nonlinear Analyses Of Tuff Masonry Walls Strengthened With Cementitious Matrix-Grid Composites. Journal of Composites for Construction, 13 (4): 243-251.

Lignola GP, Prota A, Manfredi G (2012) Numerical investigation on the influence of FRP retrofit layout and geometry on the in-plane behavior of masonry walls. Journal of Composites for Construction, 16 (6): 712-723.

Mazzotti C, Ferracuti B, Bellini A (2012) Experimental bond tests on masonry panels strengthening by FRP. In: Proc. 6th International Conference on FRP Composites in Civil Engineering CICE2012, Rome, Italy.

Mazzotti C, Ferracuti B, Bellini A (2015b) Experimental bond tests on masonry panels strengthened by FRP. Composite Structures. Submitted for publication.

Mazzotti C, Sassoni E, Bellini A, Ferracuti B, Franzoni E (2015a) Strengthening of masonry elements by FRP: Influence of brick mechanical and microstructural properties. Key Engineering Materials, 624: 330-337. 
Micelli F, De Lorenzis L, La Tegola A (2004) FRP-confined masonry columns under axial loads: experimental results and analytical model. Masonry International, 17 (3): 95-108

Modena C (2004) Design approaches of investigations for the safety and conservation of historic buildings. In: Proc. 4th International Conference on Structural Analysis of Historical Construction SAHC2004, Padova, Italy.

Oliveira DV, Basilio I, Lourenço PB (2010) Experimental behavior of FRP strengthened masonry arches. Journal of Composites for Construction, 14 (3): 312-322.

Panizza M, Garbin E, Valluzzi MR, Modena C (2012) Experimental investigation on bond of FRP/SRP applied to masonry prisms. In: Proc. 6th International Conference on FRP Composites in Civil Engineering CICE2012, Rome, Italy.

Parisi F, Lignola GP, Augenti N, Prota A, Manfredi G (2011) Nonlinear Behavior of a Masonry SubAssemblage Before and After Strengthening With Inorganic Matrix-Grid Composites. Journal of Composites for Construction, 15 (5): 821-832.

Tedeschi C, Kwiecień A, Valluzzi MR, Binda L, Zając B (2014) Thermal ageing and salt decay on bond between FRP and masonry. Materials and Structures, 47: 2051-2065.

Valluzzi MR, Modena C, de Felice G (2014) Current practice and open issues in strengthening historical buildings with composites. Materials and Structures, 47: 1971-1985.

Valluzzi MR, Oliveira D, Caratelli A, Castori G, Corradi M, de Felice G, Garbin E, Garcia D, Garmendia L, Grande E, Ianniruberto U, Kwiecień A, Leone M, Lignola GP, Lourenço PB, Malena M, Micelli F, Panizza M, Papanicolaou CG, Prota A, Sacco E, Triantafillou TC, Viskovic A, Zając B, Zuccarino G (2012) Round Robin Test for Composite-To-Brick Shear Bond Characterization. Materials and Structures, 45: 1761-1791.

Valluzzi MR, Tinazzi D, Modena C (2002) Shear behavior of masonry panels strengthened by FRP laminates. Construction and Building Materials, 16 (7): 409-416.

Valluzzi MR, Valdemarca M, Modena C (2001) Behavior of brick masonry vaults strengthened by FRP laminates. Journal of Composites for Construction, (5) 3: 163-169.

Viskovic A, Zuccarino L, Kwiecień A, Zając B (2015) Masonry Panels Composite Reinforcements with Epoxy Matrix, Inorganic Mortar Matrix and PS Polymer Matrix. Key Engineering Materials, Vol. 624, Trans Tech Publications, Switzerland, pp. 214-221.

Zając B, Kwiecień A (2014) Thermal stress generated in masonries by stiff and flexible bonding materials. In: proc 9th International Masonry Conference, Guimarães, Portugal. 